\title{
Article \\ Evaluation of Freeze Drying and Electrospinning Techniques for Saffron Encapsulation and Storage Stability of Encapsulated Bioactives
}

\author{
Fatemeh Golpira $^{1}$, Neda Maftoonazad ${ }^{2, *}$ and Hosahalli S. Ramaswamy ${ }^{1, *}$ \\ 1 Department of Food Science and Agricultural Chemistry, Macdonald Campus of McGill University, \\ 211111 Lakeshore Road, Ste Anne de Bellevue, QC H9X 3V9, Canada; fatemeh.golpira@mail.mcgill.ca \\ 2 Agricultural Engineering Research Department, Fars Agricultural and Natural Resources Research and \\ Education Center, Agricultural Research, Education and Extension Organization (AREEO), \\ Shiraz 7155863511, Iran \\ * Correspondence: n.maftoon@areeo.ac.ir (N.M.); hosahalli.ramaswamy@mcgill.ca (H.S.R.); \\ Tel.: +98-9179-122757 (N.M.); +514-398-7919 (H.S.R.); Fax: +98-7137-205107 (N.M.); +514-398-7977 (H.S.R.)
}

Citation: Golpira, F.; Maftoonazad, N.; Ramaswamy, H.S. Evaluation of Freeze Drying and Electrospinning Techniques for Saffron Encapsulation and Storage Stability of Encapsulated Bioactives. J. Compos. Sci. 2021, 5, 326 https://doi.org/10.3390/jcs5120326

Academic Editor: Francesco Tornabene

Received: 31 October 2021

Accepted: 7 December 2021

Published: 17 December 2021

Publisher's Note: MDPI stays neutral with regard to jurisdictional claims in published maps and institutional affiliations.

Copyright: (c) 2021 by the authors. Licensee MDPI, Basel, Switzerland. This article is an open access article distributed under the terms and conditions of the Creative Commons Attribution (CC BY) license (https:/ / creativecommons.org/licenses/by/ $4.0 /)$.

\begin{abstract}
Saffron extract was encapsulated into a gelatin matrix by means of electrospinning and freeze drying techniques and the degradation kinetics of bioactive compounds were evaluated during their storage at 4,24 , and $35^{\circ} \mathrm{C}$ as compared to non-encapsulated control. The encapsulation efficiency, thermal properties, storage stability, morphology, and diameter distribution of the encapsulated saffron extract were evaluated as output parameters. In general, both encapsulation techniques demonstrated superior retention of bioactive compounds compared to samples without encapsulation during the entire storage period. Electrospinning and freeze drying techniques were able to retain at least 96.2 and $93.7 \%$ of crocin, respectively, after 42 days of storage at $35{ }^{\circ} \mathrm{C}$ with the $15 \%$ saffron extract. The half-life $\left(t_{1 / 2}\right)$ time parameter for the control sample (with $15 \%$ saffron extract without encapsulation) was 22 days at $4{ }^{\circ} \mathrm{C}$ temperature, while that encapsulated by electrospinning was 138 days and that obtained for freeze drying was 77 days, The half-lives were longer at lower temperatures. The encapsulation efficiency of crocin, picrocrocin, and safranal associated with the electro-spun gelatin fibers were $76.3,86.0$, and $74.2 \%$, respectively, and in comparison, the freeze drying encapsulation efficiencies were relatively lower, at $69.0,74.7$, and $65.8 \%$, respectively. Electrospun gelatin fibers also had higher melting and denaturation temperatures of $78.3^{\circ} \mathrm{C}$ and $108.1^{\circ} \mathrm{C}$, respectively, as compared to $65.4^{\circ} \mathrm{C}$ and $93.2{ }^{\circ} \mathrm{C}$, respectively, for freeze-dried samples. Thus, from all respects, it was concluded that electrospinning was a better and more effective technique than freeze drying in terms of preserving saffron bioactive compounds.
\end{abstract}

Keywords: gelatin; saffron; bioactive compounds; differential scanning calorimetry; encapsulation efficiency; scanning electron microscopy

\section{Introduction}

Saffron, a natural source of red to orange pigments, obtained from the dried red stigma of Crocus sativus L., is one of the most expensive spices in the world. Saffron is cultivated in mild and dry climates. The main producers of saffron are Iran, Greece, India, Spain, Turkey, Morocco, Italy, China, Turkey, Azerbaijan, Egypt, and Pakistan [1]. Saffron is used extensively in different industries such as food, cosmetics, and pharmaceuticals due to its coloring, taste, aroma, antioxidant, and therapeutic properties (anti-cancer, antidepression, anti-spasmodic, and carminative). Three major compounds of saffron-crocin, picrocrocin, and safranal—are responsible for its color, aroma, and flavor, respectively [2]. This flavoring spice is quite expensive; nevertheless, its consumption is increasing because of its sensory and functional properties and bioactive compounds. Compounds of saffron are predominantly unstable and the degradation rate of crocin, picrocrocin, and 
safranal influenced by several product and processing conditions: encapsulation processes, processing conditions, moisture, proteins, metallic ions, $\mathrm{pH}$, light, enzymes, oxygen, and storage temperature [3]. Therefore, bioactive compounds of saffron should be appropriately controlled and protected against different factors to minimize their loss during processing and storage.

Encapsulation is a technique that can entrap bioactive compounds within a protective shell [4]. Encapsulation of bioactive ingredients decreases the loss of volatile components and the rate of evaporation during the drying process. Additionally, encapsulation is an effective method to improve the solubility and storage stability of bioactive compounds [5]. Through the encapsulation process, the sensitive compounds are entrapped in a core surrounded by a protective shell of another material (wall) [6]. Different methods are followed in the food industry for encapsulation: physical methods (freeze drying, spray drying, spray cooling and chilling, fluidized-bed coating, co-crystallization, and extrusion), chemical methods (molecular inclusion and interfacial polymerization) and physicochemical methods (organic phase separation, coacervation, and liposome entrapment) [7]. Garavand, et al. [8] observed that encapsulation techniques are favored when intended to protect the bioactive compounds of saffron. Microencapsulation (spray drying, freeze drying, extrusion, and emulsion systems) and nanoencapsulation (nanoemulsions, solid lipid nanoparticles and nanodispersions, nanohydrogels, electrospinning, and nanospray drying) procedures have been investigated for saffron bioactives. Azarpazhooh, et al. [9] demonstrated a successful application of the freeze drying encapsulation process for pomegranate peel bioactives that achieved good storage stability.

The most suitable techniques for encapsulation of all heat-sensitive bioactives that are water-soluble and unstable in aqueous solution is freeze drying [10,11]. Encapsulation Freeze drying has four stages including freezing, sublimation, desorption, and finally storage [12]. The freeze drying step can protect the properties of these material such as dimensions, appearance, shape, color, taste, texture, and flavor [13]. Maltodextrin, gum arabic, whey protein, and emulsifying starches are used extensively in the freeze drying encapsulation of food ingredients. Buffo and Reineccius [14] reported that encapsulated freeze-dried products had the most desirable properties as compared to products subjected to spray drying, drum drying, and tray drying. Zuidam and Shimoni [15] found that during the freeze drying process, a high-porous barrier is formed between the active compound and its surrounding environment. Ahmadian, et al. [16] evaluated different drying methods and wall structures on the physicochemical characteristics of microcapsules of saffron petal extracts. They demonstrated that higher amounts of pectin in the wall material in combination with spray drying favored an increase in the encapsulation efficiency and retention of polyphenols and the antioxidant activity of microcapsules. On the other hand, the stability of microcapsules produced by the pectin wall material and freeze drying was better.

Electrospinning is a method to produce fibers with nano- to micro-meter size particles using electrostatic forces to shape a polymer solution into a fiber format. Electro-spun fibers show unique properties including a large surface area to volume ratio and high porosity. These properties provide a good opportunity to entrap the bioactive compounds with high encapsulation efficiency and also to improve the stability of encapsulated compounds [17]. Electrospinning can be influenced by polymer solution properties (surface tension, viscosity, and electrical conductivity), processing parameters (applied voltage, the distance between the needle and the collector, and different types of needles and collectors) and environmental conditions (temperature, moisture, and relative humidity). Furthermore, there are other methods to produce nanofibers including surface grafting polymerization, polymer phase separation, atomic layer deposition, and electrospinning $[6,18,19]$. The electrospinning technique has some advantages over the other techniques such as low start-up costs, an absence of heat during the spinning process, and the simplicity of the instrument setup [20,21]. Electro-spun fibers have gained strong commercial and academic attention and have been used effectively in many applications including tissue engineering, 
air and water filtration membranes, protective clothing, artificial organs, thermal energy storage, and drug delivery [20,21]. However, the electrospinning technique is relatively new for the encapsulation of bioactive materials and their applications in different food industries. Electro-spun fibers offer an excellent choice as a carrier to encapsulate bioactive compounds because of their small diameter and organized structure [22]. Thus, in the area of food, electro-spun fiber has a strong potential to be used in the packaging, encapsulation, and controlled release of food ingredients [23]. Saffron consists of safranal, crocin, and picrocrocin as bioactive compounds. Esfanjani, et al. [24] and Rajabi, et al. [25] evaluated different types of wall materials for the encapsulation of the three bioactive compounds of saffron using the spray drying method in order to attain higher encapsulation efficiency. Electrospinning has been used for the encapsulation of other carotenoids as well. For instance, Horuz and Belibağlı [26] demonstrated the use of the electrospinning technique for the encapsulation of total carotenoids such as lycopene and $\beta$-carotene extracted from tomato peel in order to stabilize them into gelatin nanofibers. Dehcheshmeh and Fathi [5] used electro-spun zein and tragacanth to improve the thermal properties and stability of safranal, which is the main volatile oil of saffron. The encapsulation of saffron extract, which includes three different bioactive compounds, is a more complex procedure.

It was recommended to use natural polymers for the encapsulation of bioactive compounds in the food industry due to their biocompatibility and non-toxicity as compared to synthetic polymers $[27,28]$. Electro-spun fibers have been successfully produced from natural polymer solutions such as gelatin, pectin, alginate, tragacanth, chitosan, pullulan, amaranth protein, and zein $[19,22,26,29]$. Gelatin is used extensively as a wall material for the encapsulation of bioactive compounds due to its unique properties such as hydration (solubility and swelling), gelling (texturizing, gel formation, water binding capacity, and thickening) and surface behavior (film-forming capacity, emulsion formation, and stabilization). Other advantages of gelatin are its relatively low cost, availability, and acceptance by the food industry [30]. Maftoonazad, et al. [31] recently developed and evaluated antibacterial electro-spun pea protein isolate-polyvinyl alcohol nanocomposite mats incorporated with cinnamaldehyde to provide bacterial protection. Food-derived and food-approved solvents should be used for the encapsulation of materials with food-related applications, although during the fiber generation process, it is generally assumed that the solvent is mostly evaporated [29]. Finally, since bioactive compounds of saffron are susceptible to degradation when stored for extended times at different temperatures, they need to be protected during processing and storage.

The main objective of this research was to develop and evaluate the encapsulation of bioactive compounds of saffron extract at different concentrations $(5,10$, and $15 \% w / w)$ using two different techniques (freeze drying and electrospinning). The encapsulation efficiency, thermal properties, morphology, and diameter distribution of the encapsulated and non-encapsulated samples were determined as performance indicators. The storage stability of crocin was studied at different temperatures $\left(4,24\right.$, and $\left.35^{\circ} \mathrm{C}\right)$ for up to 42 days.

\section{Materials and Methods}

\subsection{Materials}

Saffron was obtained from a Persian supermarket in Montreal, Canada. Type A gelatin powder from bovine skin, formic acid, and magnesium chloride were obtained from Sigma-Aldrich (St. Louis, MO, USA).

\subsection{Preparation of Saffron Extracts}

For the extraction of saffron bioactive compounds, the procedure of Selim, et al. [32] was followed with some modifications. A quantity of $12 \mathrm{~g}$ of saffron powder was mixed with $500 \mathrm{~mL}$ water in a dark colored bottle under continuous shaking in an incubator (Gravity Convention Incubator, Precision Scientific, Inc., Winchester, VA, USA) at $25^{\circ} \mathrm{C}$ for $24 \mathrm{~h}$. The extract was centrifuged (IEC-Centra ${ }^{\circledR}$ CL2, Needham Heights, MA, USA) at $2000 \times g$ for $15 \mathrm{~min}$ followed by filtration under vacuum. The prepared extract was 
freeze-dried at $-30{ }^{\circ} \mathrm{C}$ (freeze-drier VirTis Co., Gardiner, NY, USA) for 6 days. Some additional details about the freeze drying process are detailed in Section 2.5.2. The freeze dried powders were kept in a dark colored bottle at $-18{ }^{\circ} \mathrm{C}$ until use.

\subsection{Preparation of Polymer Solution}

Gelatin solution $(25 \% w / w)$ was prepared by dissolving gelatin powder in formic acid followed by the addition of three different concentrations $(5,10,15 \% w / w)$ of freeze-dried saffron extract powder to the gelatin-formic acid solution. These solutions were named Ge-S5\%, Ge-S10\%, and Ge-S15\%, respectively. A gelatin solution without saffron extract was also prepared for the production of gelatin fiber as a control sample. All solutions were stirred with a magnetic stirrer $(120 \mathrm{rpm})$ for about $1 \mathrm{~h}$ at room temperature [26].

\subsection{Rheological Properties of the Polymer Solution}

The rheological properties of the polymer solutions were measured using a controlled strain cone and plate geometry rheometer (TA instrument, New Castel, DE, USA) at $25^{\circ} \mathrm{C} \pm 1$. The plate diameter and the cone angle were $40 \mathrm{~mm}$ and $2^{\circ}$, respectively. The shear rate was ramped from 1 to $100 \mathrm{~s}^{-1}$ in $60 \mathrm{~s}$. The shear stress $(\tau)$ and shear rate $(\dot{\gamma})$ data were gathered (Maftoonazad et al., 2019). The shear stress, shear rate and apparent viscosity data were analyzed by the power law model using Equation (1) for different shear rates:

$$
\eta=\mathrm{k}(\dot{\gamma})^{\mathrm{n}-1}
$$

where $\eta$ is apparent viscosity $(\mathrm{Pa} \cdot \mathrm{s})$.

\subsection{Encapsulation Process}

\subsubsection{Electrospinning}

Polymer solutions were electro-spun using an electrospinning instrument (Invenso Inc., Istanbul, Turkey) as detailed in Maftoonazad, Shahamirian, John and Ramaswamy [31]. Briefly, a $10 \mathrm{~mL}$ disposable plastic syringe containing the polymer solution was connected to the stainless steel needle with an internal diameter of $16 \mu \mathrm{m}$, and the needle was directed toward the collector. The plastic syringe was placed horizontally on a digitally controlled syringe pump that was equipped with a variable high-voltage $0-30 \mathrm{kV}$ power supply. The positive electrode of the power supply was attached to a stainless-steel needle, while the ground electrode was connected to the steel collector covered with nonstick aluminum foil. The polymer jet was generated from the Taylor cone that travelled in the air and it collected on the stainless steel collector plate. Electrospinning parameters (feed rate, applied voltage, and tip to collector distance) were fixed after carrying out some preliminary tests. The feed rate, applied voltage, and tip to collector distance were maintained at $2 \mathrm{~mL} / \mathrm{min}, 18 \mathrm{kV}$, and $15 \mathrm{~cm}$, respectively. The electrospinning process was conducted at $25 \pm 1{ }^{\circ} \mathrm{C}$ under $40 \%$ relative humidity in the laboratory. After electrospinning, fibers were removed and kept at $-18{ }^{\circ} \mathrm{C}$ until use for characterization analysis.

\subsubsection{Freeze Drying Procedure}

In this technique, after preparation of gelatin solutions with and without saffron extract, all liquid samples were frozen in a freezer (top-freezer refrigerator Rona Co., Boucherville, QC, Canada) $\left(-18{ }^{\circ} \mathrm{C}\right)$ for $24 \mathrm{~h}$ and subsequently at $-80^{\circ} \mathrm{C}$ for $24 \mathrm{~h}$. The first stage of drying was performed by keeping the product at a pressure of $0.42 \mathrm{mbar}$ at $30^{\circ} \mathrm{C}$. The second stage of drying was carried out by reducing the pressure to $0.05 \mathrm{mbar}$ and increasing the shelf temperature to $40^{\circ} \mathrm{C}$. To monitor the process, a type $\mathrm{T}$ thermocouple and also a Pirani gauge were used.

After removing the samples from the freeze-dryer chamber, dried specimens were ground by a pestle and mortar, followed by sieving of the powders using a stainless steel sifter with a $0.71 \mathrm{~mm}$ mesh. Freeze-dried powders were stored in amber glass jars in a freezer $\left(-18^{\circ} \mathrm{C}\right)$ until further use. 


\subsection{Characterization of Electro-Spun Fibers and Freeze-Dried Powders}

\subsubsection{Scanning Electron Microscopy}

The morphology and diameters of the electro-spun fibers and freeze-dried particles were analyzed by means of scanning electron microscopy (S-4700 FEG-SEM, Hitachi Ltd., Mississauga, ON, Canada) at room temperature. For electro-spun samples, a small amount of fiber mat $(5 \times 5 \mathrm{~mm})$ was placed onto specimen stubs using a two-sided adhesive tape with accelerating voltage of $5 \mathrm{kV}$ and photographed at different magnifications. Fiber diameter distribution was determined by randomly counting 110 parts of fiber per SEM image using the Image J analysis software [31].

\subsubsection{Determination of Encapsulation Efficiency}

Encapsulation efficiency (EE) was determined according to the methods described by Esfanjani, Jafari, Assadpoor and Mohammadi [24] and Aceituno-Medina, Mendoza, Lagaron and López-Rubio [29] with some modifications, which were based on the differences in the light density of soluble bioactive compounds of saffron extract at three different wavelengths. For calculation of the amount of encapsulated crocin, picrocrocin, and safranal in gelatin fibers or gelatin particles $\left(C_{t}\right)$, approximately $3 \mathrm{mg}$ of sample was added into $5 \mathrm{~mL}$ of ethanol-hexane mixture $(50: 50, v / v)$ and stirred at $12 \times \mathrm{g}$ during $10 \mathrm{~min}$ to remove the free saffron extract from the surface of the encapsulated fibers or encapsulated particles. Then, the mixture was centrifuged at $\sim 2000 \times g$ for $10 \mathrm{~min}$ at room temperature to separate the sample from the solution. The precipitated sample was collected and placed in a beaker with $5 \mathrm{~mL}$ distilled water. Then, it was stirred for $10 \mathrm{~min}$ at $12 \times \mathrm{g}$ to dissolve the fibers or particles in order to release the encapsulated bioactive compounds of saffron from the gelatin membrane. The absorbance of this solution was read at 440, 330, and $257 \mathrm{~nm}$ using a UV-Vis spectrophotometer (SP-3000nano, OPTIMA, Japan) equipped with quartz cells to measure the amount of encapsulated crocin, safranal, and picrocrocin in gelatin fiber or particle, respectively. Absorption measurements were conducted in triplicate for each compound. The results were expressed as $\mathrm{A}_{1 \mathrm{~cm}}^{1 \%}(\lambda \max )$ according to Equations (2) and (3) for the calculation of EE of different bioactive compounds of saffron [24].

To measure the amount of crocin, safranal, and picrocrocin, saffron extract solution $(1 \% w / v)$ was prepared by dissolving $1 \mathrm{~g}$ saffron extract in $100 \mathrm{~mL}$ distilled water at room temperature. The mixture was stirred continuously with mechanical stirring at $12 \times g$ for 15 min until the saffron powder completely dissolved. The amount of crocin, safranal, and picrocrocin in the saffron extract was measured by reading the absorbance of the prepared saffron extract solution through UV-Vis spectrophotometry at 440, 330, and $257 \mathrm{~nm}$, respectively. The results were calculated based on Equation (3).

$$
\begin{aligned}
\operatorname{EE}(\%) & =\left(C_{t} / C_{0}\right) \times 100 \\
C_{0} \text { and } C_{t}=A_{1 \mathrm{~cm}}^{1 \%}(\lambda \max ) & =(\mathrm{A} \times 10,000) /(\mathrm{m} \times(100-\mathrm{H}))
\end{aligned}
$$

where $C_{t}$ is the amount of encapsulated crocin, picrocrocin, and safranal in the gelatin fiber or gelatin particle; $\mathrm{C}_{0}$ is the initial amount of crocin, picrocrocin, and safranal in the saffron extract; $\lambda \max$ is the maximum absorbance of crocin, safranal, and picrocrocin at 440,330 , and $257 \mathrm{~nm}$, respectively; $\mathrm{A}$ is the absorbance value of picrocrocin, safranal and crocin at the specific wavelength; $\mathrm{m}$ and $\mathrm{H}$ are the sample weight $(\mathrm{g})$ and the moisture content of the sample, respectively [24]. The moisture contents of all the powders were evaluated by using the vacuum dying method [33].

\subsubsection{Stability of Encapsulated Saffron under Accelerated Storage Condition}

Encapsulated saffron extract powder in gelatin fibers by electrospinning and freeze drying techniques and the non-encapsulated extract (as a control sample) were transferred to plastic centrifuge tubes and kept in sealed desiccators with saturated salt solutions of magnesium chloride at $33 \%$ relative humidity. Then, desiccators were stored in 4,24 and 
$35{ }^{\circ} \mathrm{C}$ in the absence of light for up to 42 days to study the effect of temperature on the storage stability of crocin in the saffron extract.

To measure the loss of encapsulated and un-encapsulated crocin during storage, the same procedure was followed for sample preparation as explained in Section 2.6.2. The test was conducted after $7,14,21,28,35$, and 42 days storage. The UV-Vis spectrophotometer (SP-3000nano, OPTIMA, Tokyo, Japan) was used to measure the change in the retention of encapsulated and un-encapsulated crocin. In fact, crocin was expressed based on changes in the light density of this compound at $440 \mathrm{~nm}$ (ISO/TS 3632 procedure, 2003). The amount of this compound was calculated using Equation (3).

\subsubsection{Thermal Properties}

The thermal behavior of the saffron extract and neat gelatin powder, as well as the electro-spun gelatin fibers and freeze-dried gelatin particles with and without saffron extract, was analyzed using a differential scanning calorimeter (Pyris DSC-6 Perkin Elmer Ltd., Norwalk, CA, USA). In this experiment, quantities of about 6-7 mg of the samples were weighed and placed in an aluminum pan. The sealed samples were heated over a range from 20 to $200^{\circ} \mathrm{C}$ at a scanning rate of $10^{\circ} \mathrm{C} / \mathrm{min}$ under nitrogen gas flow (Shao et al., 2007 [34]). An empty aluminum pan was considered as a reference. Thermal property measurements of the samples were conducted in triplicate.

\subsubsection{Kinetics of Degradation of Crocin in Saffron Extract}

To study the degradation kinetics of encapsulated crocin in gelatin matrix and nonencapsulated crocin in saffron extract powder, samples were stored at different conditions based on the procedure that was explained in detail in Section 2.6.3. Degradation rate constants $(\mathrm{k})$ was determined from the slope of a plot of the logarithm of crocin retention at a given temperature against time. The half-life $\left(t_{1 / 2}\right)$ was also calculated from the $k$ value using Equations (4) and (5):

$$
\begin{aligned}
& C_{d}=C_{i} \exp (k d) \\
& t_{1 / 2}=-\ln 0.5 / k
\end{aligned}
$$

where $C_{i}$ is the initial concentration of crocin in saffron extract and $C_{d}$ is the saffron extract concentration after storage for a period of time (days), while $\mathrm{k}$ is the first-order kinetic constant [34].

\subsection{Statistical Analysis}

The results were analyzed statistically using SPSS Version 25 (SPSS Inc., Chicago, IL, USA). One-way analysis of variance and Tukey's test at the confidence level of $p<0.05$ were applied to determine the significant difference in the average encapsulation efficiencies, thermal behaviors, storage stabilities, and diameters of electro-spun gelatin fibers or freeze-dried powders with and without saffron extract. The results were represented as mean \pm standard deviation in the form of figures and tables. Each sample was tested in triplicate.

\section{Results and Discussions}

\subsection{Apparent Viscosity of Polymer Solutions}

The flow curves (shear stress/shear rate) for the different polymer solutions are shown in Figure 1; they clearly demonstrate a Newtonian behavior (linear relationship between shear rate and shear stress). Table 1 summarizes the viscosity data of gelatin solutions with different concentrations of saffron extract. Rheology data (Table 1) indicated that the addition of saffron extract to the gelatin solution slightly altered the viscosity of the solution; however, no significant differences $(p>0.05)$ were found between different treatments since the formic acid used in the solution maintained the gelatin solution rather that it becoming diluted at room temperature. 


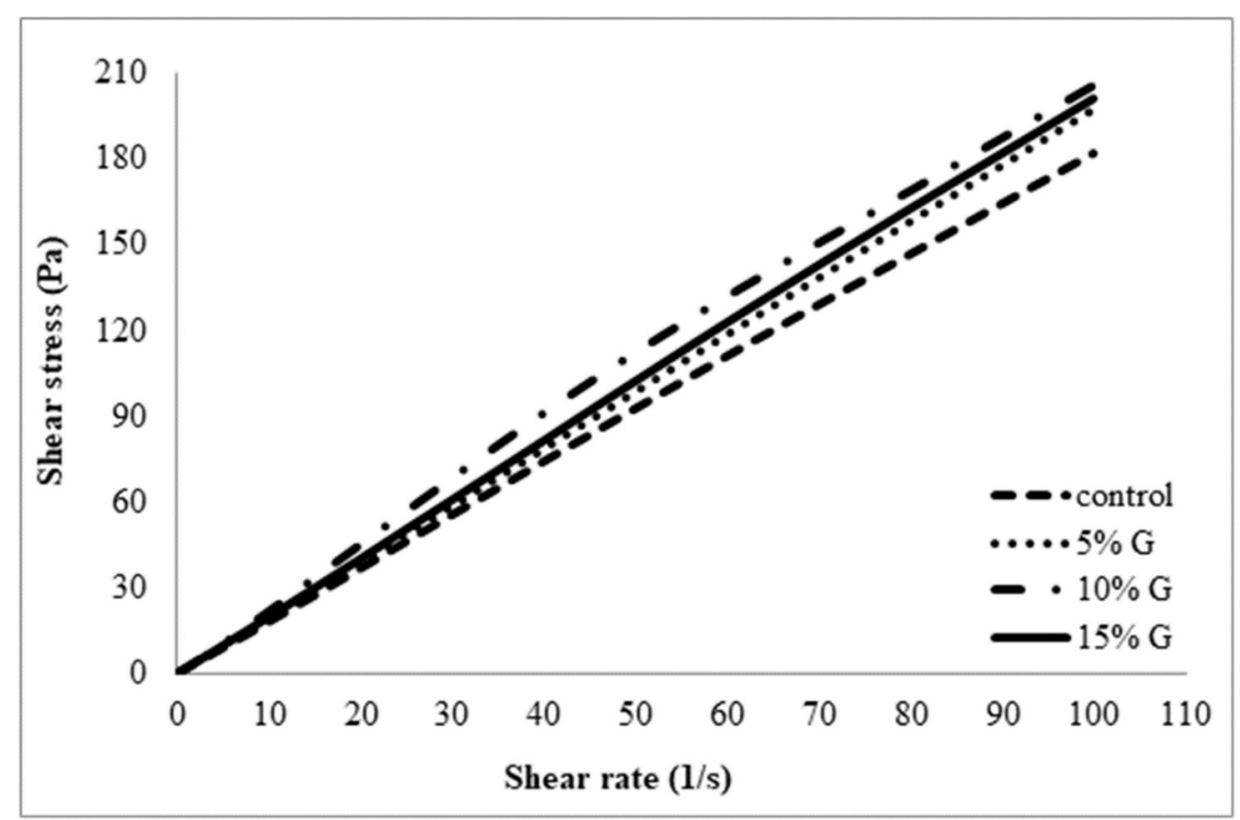

Figure 1. Shear stress vs. shear rate curves for gelatin solution with different concentrations of the saffron extract (5-15\%) and control (without saffron extract).

Table 1. Viscosity of gelatin solutions, gelatin fibers, and gelatin particle diameters with and without saffron extract.

\begin{tabular}{cccc}
\hline Encapsulation Technique & Sample & Diameter (um) & Viscosity (Pa.s) \\
\hline \multirow{3}{*}{ Electrospinning } & Ge fiber & $0.75 \pm 0.34^{\mathrm{d}}$ & $1.87 \pm 0.02^{\mathrm{a}}$ \\
& Ge-S5\% & $1.05 \pm 0.69^{\mathrm{c}}$ & $1.90 \pm 0.03^{\mathrm{a}}$ \\
& Ge-S10\% & $1.70 \pm 0.5^{\mathrm{b}}$ & $1.98 \pm 0.02^{\mathrm{a}}$ \\
& Ge-S15\% & $2.04 \pm 1.07^{\mathrm{a}}$ & $1.98 \pm 0.05^{\mathrm{a}}$ \\
\hline \multirow{3}{*}{ Freeze drying } & Ge particle & $152 \pm 40.6^{\mathrm{b}}$ & $1.87 \pm 0.02^{\mathrm{a}}$ \\
& Ge-S5\% & $163 \pm 57.2^{\mathrm{b}}$ & $1.90 \pm 0.03^{\mathrm{a}}$ \\
& Ge-S10\% & $195 \pm 68.7^{\mathrm{a}}$ & $1.98 \pm 0.02^{\mathrm{a}}$ \\
& Ge-S15\% & $217 \pm 86.1^{\mathrm{a}}$ & $1.98 \pm 0.05^{\mathrm{a}}$ \\
\hline
\end{tabular}

Small letters within the same column indicate significant differences $(p<0.05)$.

\subsection{Scanning Electron Microscopy (SEM)}

The morphology and diameter (particle size) distributions of fibers and freeze-dried particles evaluated by scanning electron microscopy are shown in Figure 2 with SEM images of electro-spun gelatin fibers and freeze-dried particles with and without the saffron extract. The results show that during the electrospinning process, the bioactive compounds of saffron dispersed uniformly and did not cause any phase separation. SEM images 2a to $2 \mathrm{~d}$ demonstrated that all fibers were smooth, bead free, and homogeneously distributed. In addition, no significant differences were observed between the morphology of fibers containing saffron extract as compared to gelatin fibers without saffron extract (control).

The particle size/shape distribution an important property of powders. Freeze-dried gelatin particles with and without the saffron extract showed similar morphologies with irregular structures, surface dents, and indentations (Figure 2e-h). These figures show that all samples with saffron extract had breakages, cracks, and holes on the surface of particles due to the mechanical pressure during the grinding process, as also observed in [9]. Kaushik and Roos [35] reported that the presence of dents and cracks on the surface of freeze-dried particles influence the powder flowability, encapsulation efficiency, and storage stability of encapsulated compounds. Therefore, morphological differences can influence the encapsulation properties because differences in the surface area of the wall 
material lead to the degradation of the encapsulated compounds [36]. A specific/standard protocol may need to be adopted in industry to produce a product of consistent quality.

(a)
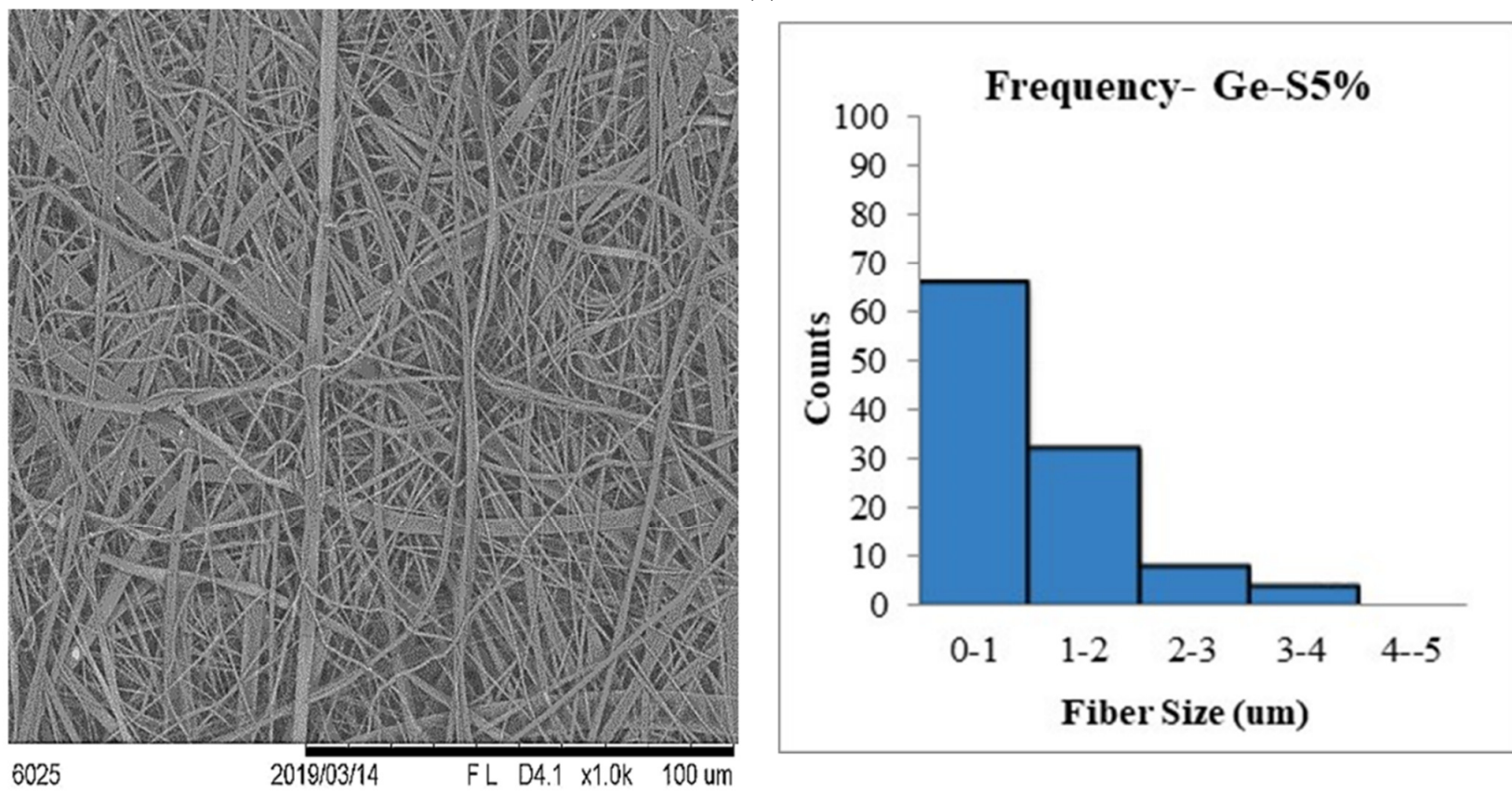

(b)
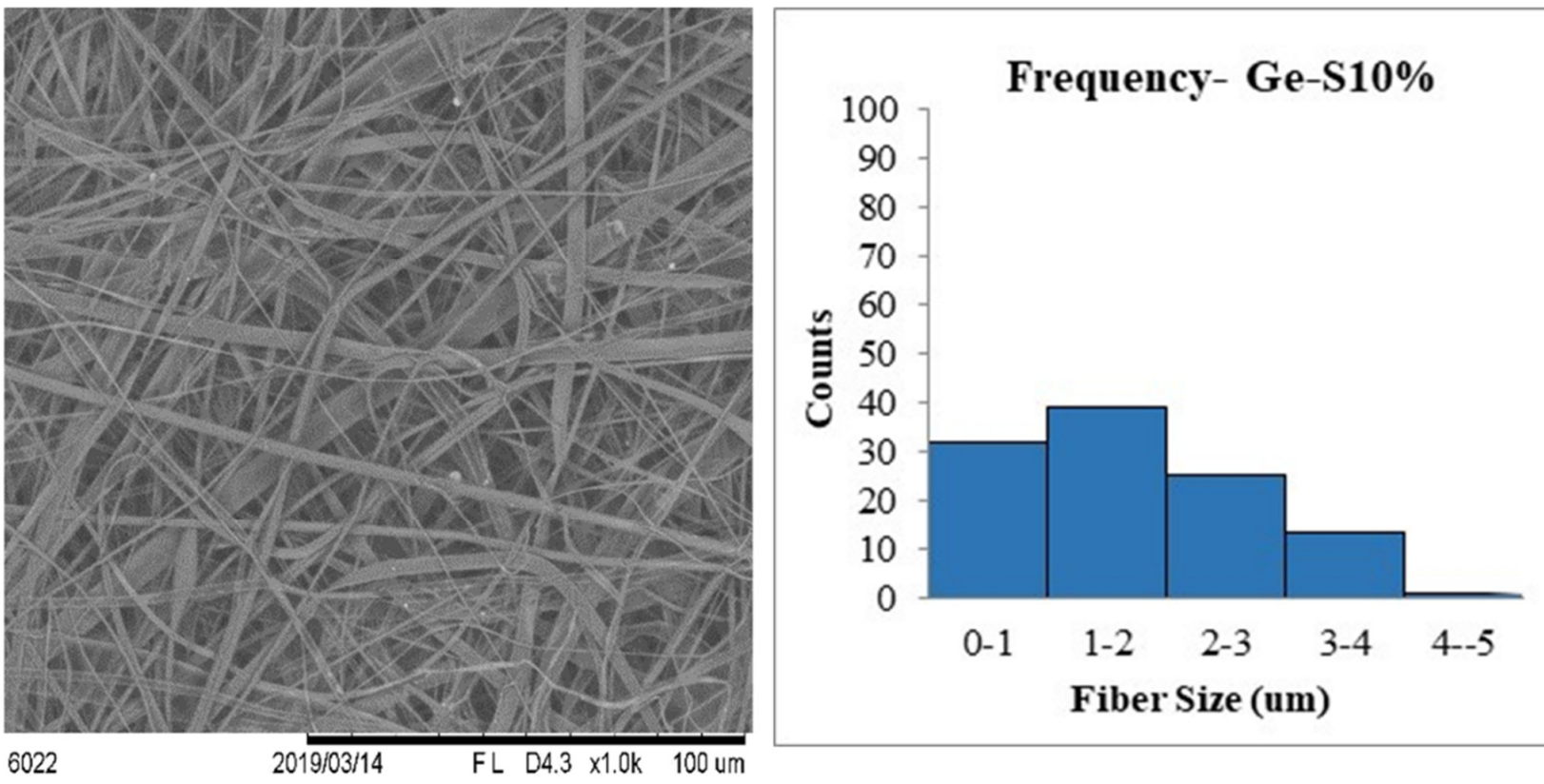

Figure 2. Cont. 
(c)
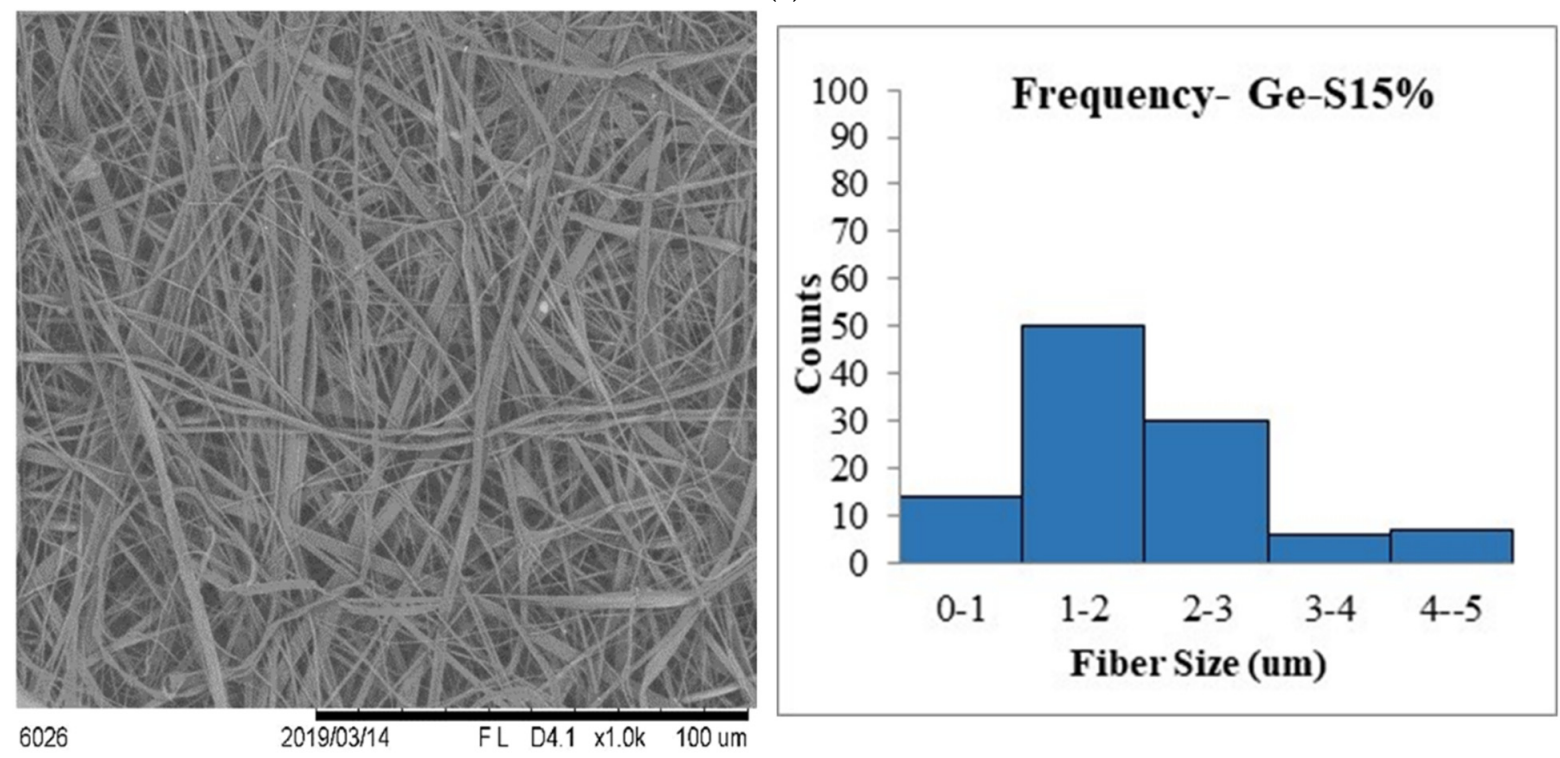

(d)
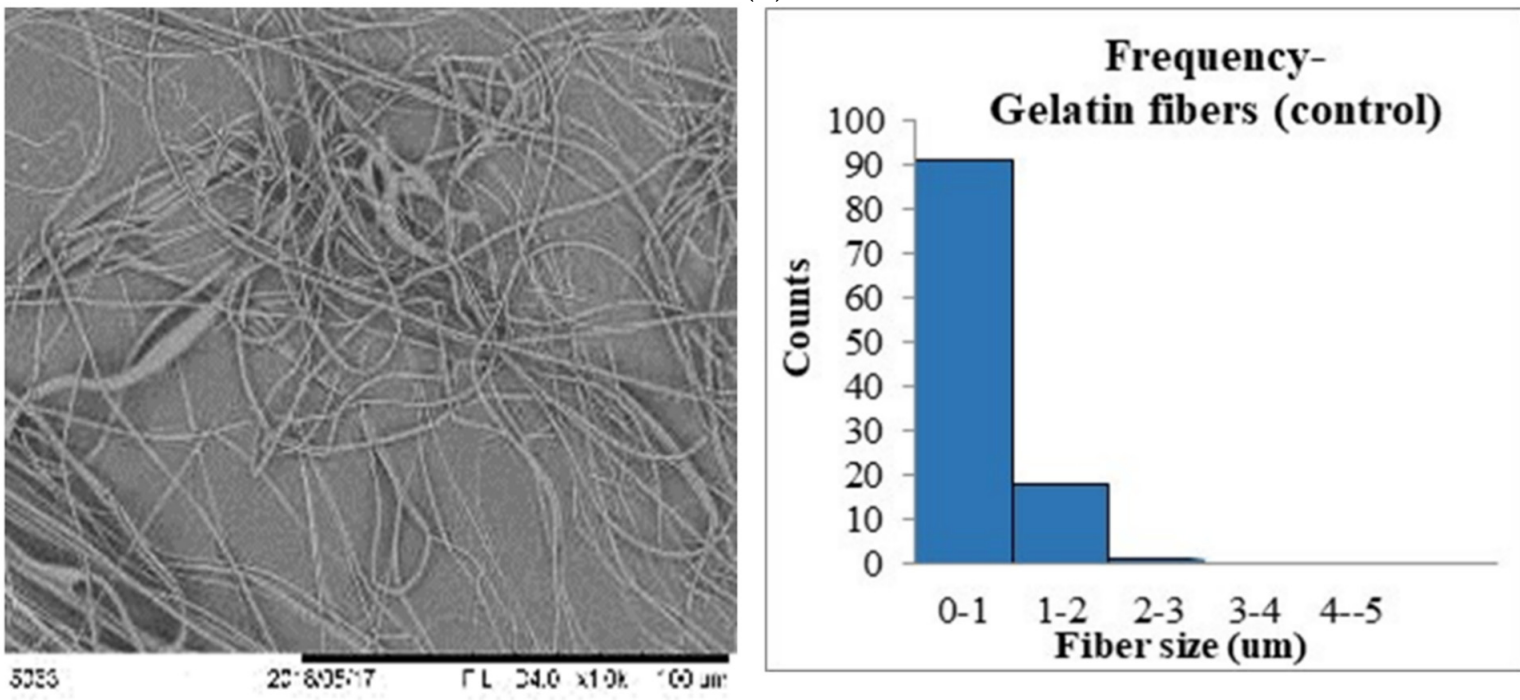

(e)
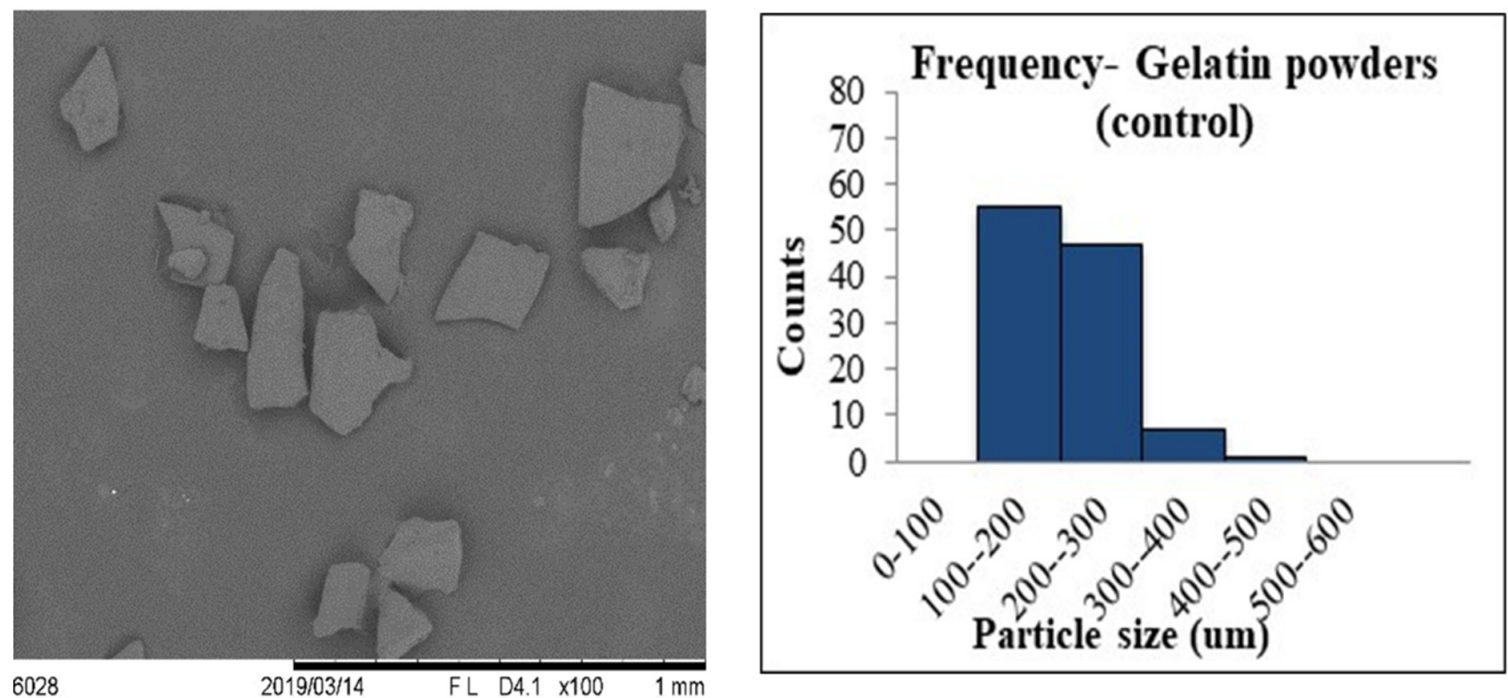

Figure 2. Cont. 
(f)
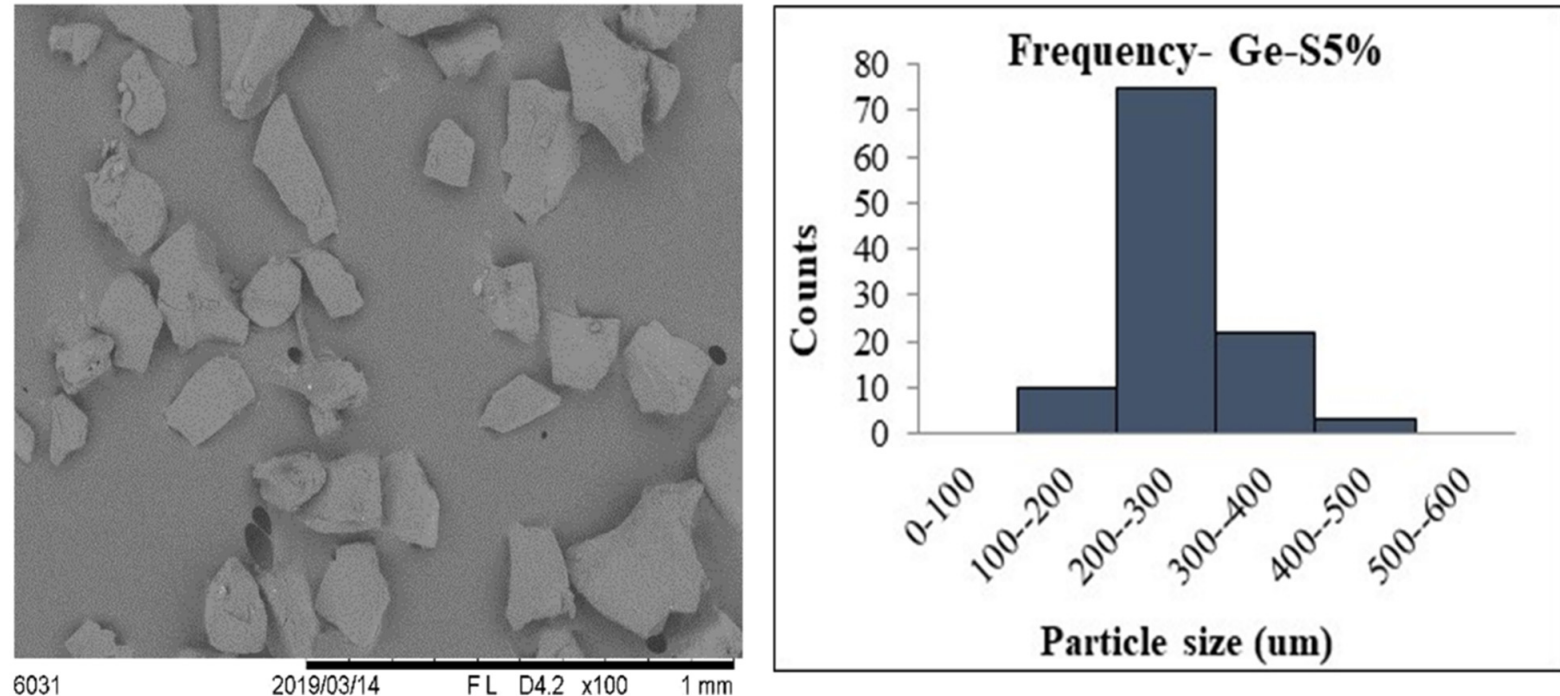

(g)
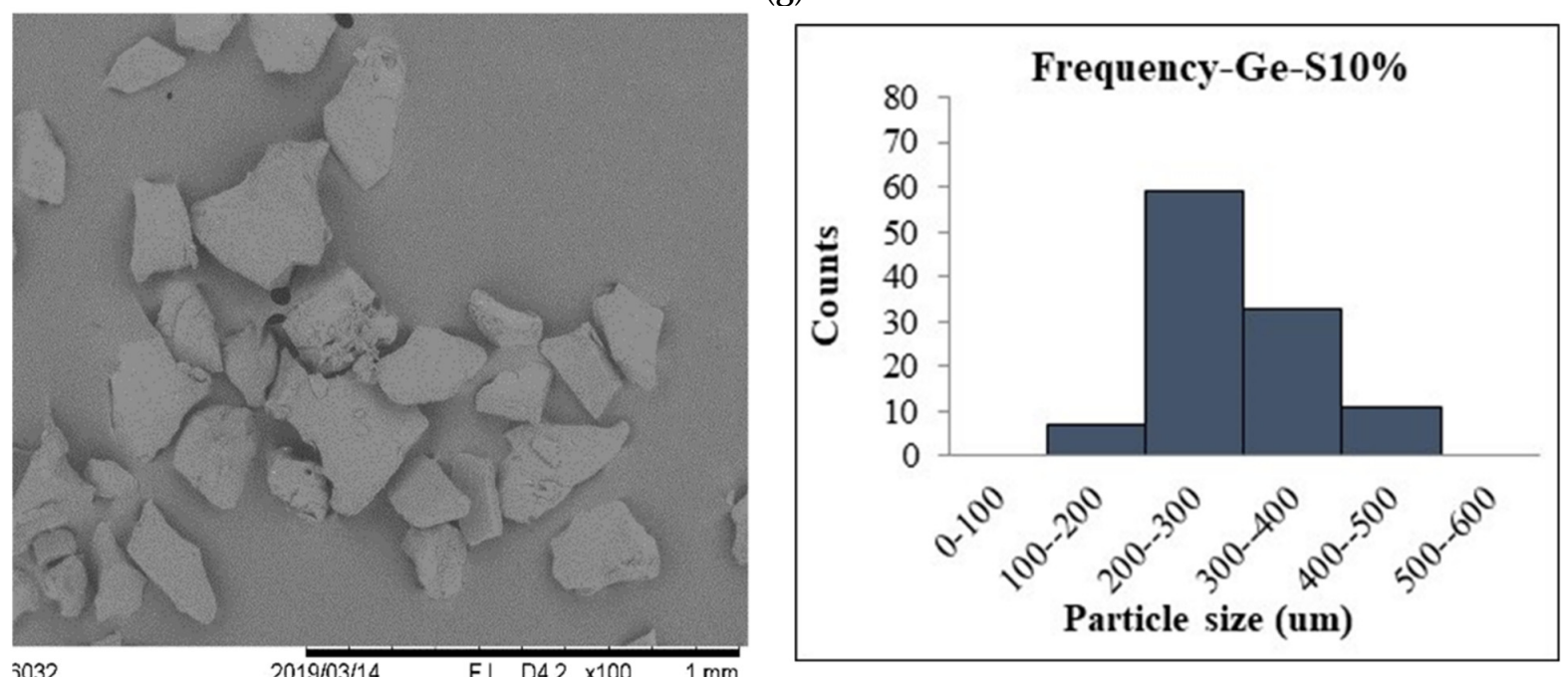

(h)
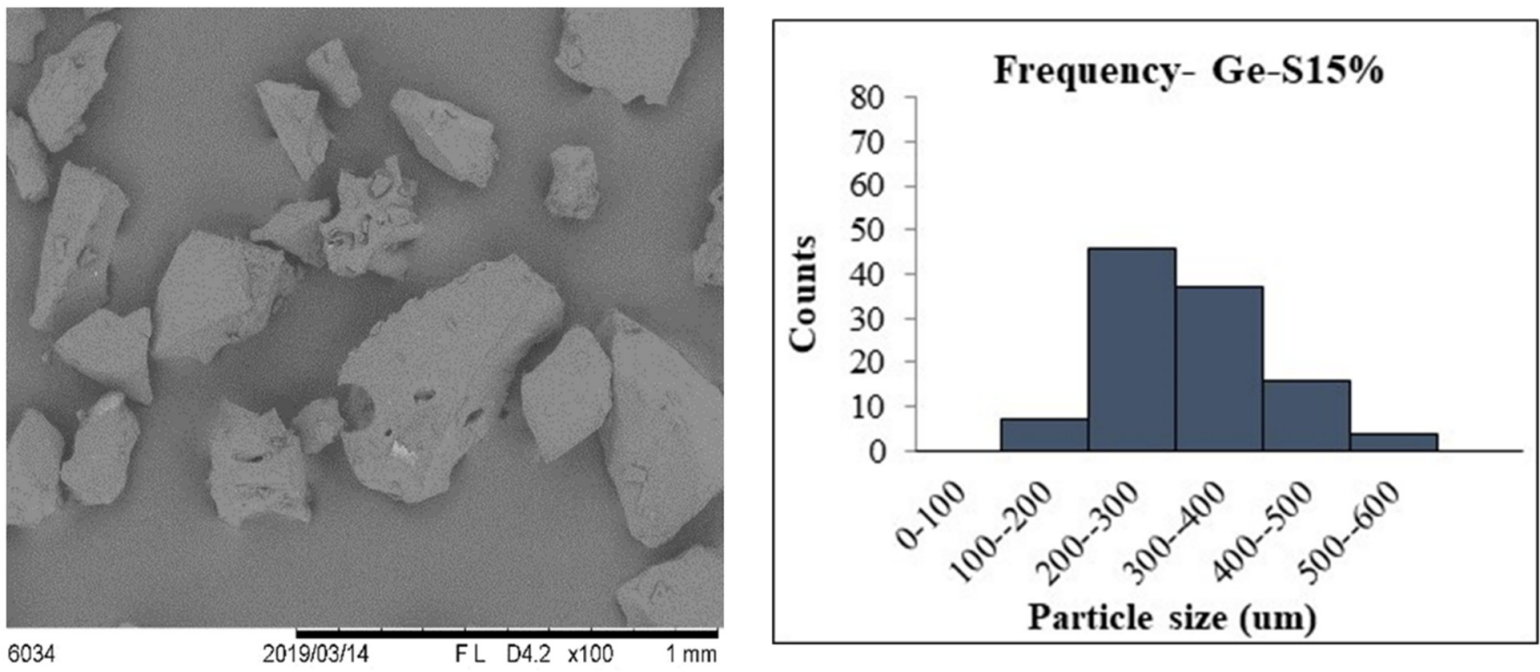

Figure 2. SEM images of (a) Ge fiber-S5\%, (b) Ge fiber-S10\%, (c) Ge fiber-S15\%, (d) Ge fiber-S0\% (at 2000× magnification), (e) Ge particle-S5\%, (f) Ge particle-S10\%, (g) Ge particle-S15\%, and (h) Ge particle-S0\% (at 100× magnification). 
Table 1 also indicates the effect of saffron extract concentration on fiber and particle size (diameter). Fiber diameter provides important information about the uniformity of the fibers. The results show that through the addition of saffron extract to the neat electrospun gelatin fiber, the diameters of fibers increased significantly $(p<0.05)$. Besides, by increasing the concentration of saffron extract from 5 to $15 \%$, the average diameter of the fibers increased significantly $(p<0.05)$ from $1.05 \pm 0.69 \mu \mathrm{m}$ to $2.04 \pm 1.07 \mu \mathrm{m}$, respectively. The thicker diameters of electro-spun gelatin fibers at higher concentrations of saffron extract are likely to be due to the increased solid contents in the feed solution. The same results were also reported by Horuz and Belibağlı [26], who observed that fiber diameters increased significantly as a result of the addition of tomato peel extract to the electrospun gelatin fibers. Shao, et al. [37] found that higher concentrations of tea polyphenols in pullulan-CMC electro-spun fibers resulted in thicker fiber diameters with higher uniformity. Suwantong, et al. [38] reported that fiber diameters can be affected by the viscosity of the solution. Therefore, higher viscosity is expected to result in thicker fiber diameter. The static charges also influence the fiber diameter through the electrospinning process [26]. They affect the whipping motion on a jet surface via a reduction in the conductivity of the polymer solution leading to an increase in the capacity of the polymer solution on the tip of the needle [39]. As a result, electro-spun fibers with thicker diameters will be produced.

Powder particles demonstrated a larger size range, with particle size distributions ranging from $151 \pm 40.6$ to $217 \pm 86.1 \mu \mathrm{m}$ (Table 1 ). The results show that by increasing the concentration of saffron extract from 5 to $15 \%$, the size of particles increased significantly $(p<0.05)$. According to Table 1, the average particle size for samples containing $15 \%$ saffron extract was $217 \pm 86.1 \mu \mu \mathrm{m}$, which was significantly higher than those obtained with $5 \%$ $(163 \pm 57.2 \mathrm{um})$ and $0 \%(152 \pm 40.6 \mu \mathrm{m})$ saffron extract concentration. Additionally, the shape, size, and morphology of the matrix were affected by encapsulation techniques, due to the different conditions in each method.

Khazaei, et al. [40] reported that freeze drying can change the original morphology of material due to the lyophilisation process. The results of this study were in agreement with those of $[25,41]$ who found that the size of particles increased when the total solids content increased in the polymer solution. This phenomenon can be explained by the viscosity of the solution, which increases through the addition of higher amounts of solids. Chranioti, et al. [42] encapsulated saffron extract in different polysaccharide gums using the freeze drying method and found that the samples had an amorphous glass-like structure that resulted in the preservation of the encapsulated compounds against oxygen and heat.

\subsection{Encapsulation Efficiency (EE)}

One of the main quality parameters of encapsulation that distinguishes the potential of a wall material to protect the core material inside the capsule is encapsulation efficiency [43]. Table 2 shows the effects of saffron extract concentrations on the encapsulation efficiency of crocin, picrocrocin, and safranal in electro-spun gelatin fibers and freeze-dried gelatin particles. The results show that by increasing the concentration of saffron extract, the encapsulation efficiency of the three major components of saffron into gelatin increased significantly $(p<0.01)$. The concentration of saffron extract had a positive effect on the encapsulation efficiency in both techniques.

The encapsulation efficiency of picrocrocin in electro-spun gelatin fibers was $71.2 \pm 1.36$, $79.0 \pm 0.95$, and $86.0 \pm 1.0$ at the concentrations of 5,10 , and $15 \%$ of saffron extract, respectively. Regarding safranal and crocin, their encapsulation efficiencies varied from $63.5 \pm 0.55$ to $74.2 \pm 0.68$ and from $68.0 \pm 0.78$ to $76.3 \pm 1.52$, respectively, by increasing the saffron extract concentration. The encapsulation efficiency of picrocrocin was, therefore, significantly $(p<0.05)$ higher than safranal and crocin at a specific concentration of saffron extract.

The amount of crocin, picrocrocin, and safranal trapped into the freeze-dried gelatin matrix was 69.0, 74.7, and 65.8\%, respectively, at $15 \%$ saffron extract, clearly lower than observed with electro-spin technology. The gelatin matrix retained the highest $(p<0.05)$ 
amount of picrocrocin, as compared to crocin and safranal, independently of the saffron extract concentration. The lowest value, 51.7 to $65.8 \%$, of encapsulated safranal as the volatile compound as compared to 59.2 to 69.0 and 62.6 to $74.7 \%$ for crocin and picrocrocin, respectively, was related to its sensitivity and instability during the encapsulation procedure.

Table 2. Effect of different concentrations of saffron extract on the encapsulation efficiency of crocin, picrocrocin, and safranal through electrospinning and freeze drying encapsulation techniques.

\begin{tabular}{ccccc}
\hline Encapsulation Technique & Sample & EE\% of Picrocrocin & EE\% of Safranal & EE\% of Crocin \\
\hline \multirow{3}{*}{ Electrospinning } & Ge-S5\% & $71.2 \pm 1.36^{\mathrm{aA}}$ & $63.5 \pm 0.55^{\mathrm{aB}}$ & $68.1 \pm 0.78^{\mathrm{aC}}$ \\
& Ge-S10\% & $79.0 \pm 0.95^{\mathrm{bA}}$ & $67.8 \pm 1.06^{\mathrm{bC}}$ & $71.5 \pm 0.66^{\mathrm{bB}}$ \\
& Ge-S15\% & $86.0 \pm 1.00^{\mathrm{cA}}$ & $74.2 \pm 0.68^{\mathrm{cB}}$ & $76.3 \pm 1.52^{\mathrm{cB}}$ \\
\hline \multirow{2}{*}{ Freeze drying } & Ge-S5\% & $62.6 \pm 0.50^{\mathrm{cA}}$ & $51.7 \pm 1.15^{\mathrm{cC}}$ & $59.2 \pm 1.00^{\mathrm{cB}}$ \\
& Ge-S10\% & $68.7 \pm 0.57^{\mathrm{bA}}$ & $59.7 \pm 2.08^{\mathrm{bB}}$ & $61.6 \pm 0.53^{\mathrm{bB}}$ \\
& Ge-S15\% & $74.7 \pm 1.15^{\mathrm{aA}}$ & $65.8 \pm 0.76^{\mathrm{aC}}$ & $69.0 \pm 0.95^{\mathrm{aB}}$ \\
\hline
\end{tabular}

Small letters within the same column for each method indicate significant differences $(p<0.05)$. Capital letters within the same row for each method indicate significant differences $(p<0.05)$.

The results showed that during the electrospinning and freeze drying process, almost 70 and $60 \%$ of the saffron extract could be encapsulated into gelatin, respectively; however, the encapsulation efficiency of the freeze drying technique was lower than that of the electrospinning technique, which might be due to the changes in morphology caused by the freeze drying process. In fact, mechanical stress during the grinding procedure might also have broken the wall material (gelatin) that entrapped the bioactive compounds of saffron and led to the release of encapsulated compounds. Therefore, the encapsulation techniques were demonstrated to be fundamental in terms of the efficacy of encapsulation. An earlier study also showed the electrospinning technique to be more effective for the encapsulation of bioactive compounds with the highest retention of the core material inside the wall material and less quantity on the surface of nanofibers compared to other encapsulation methods such as coacervation dispersion and emulsification [44].

The results of this study were very comparable to those reported by Dehcheshmeh and Fathi [5] for the encapsulation of safranal into a zein-tragacanth nanofiber. They also found that by increasing the concentration of saffron extract from 5 to $10 \%$, the encapsulation efficiency (EE) increased from 68 to $90 \%$ in zein-tragacanth nanofiber. Our findings are also in agreement with the results of Horuz and Belibağl1 [26], who reported that a higher concentration of carotenoid extract from tomato peel resulted in a higher EE of carotenoid in gelatin nanofiber when using the electrospinning technique. Thus, it can be concluded that the encapsulation efficiency was largely dependent on the core material concentration.

Rajabi, Ghorbani, Jafari, Mahoonak and Rajabzadeh [25] reported that the encapsulation efficiency of three different bioactive compounds of saffron was increased by increasing the total solids content in the polymer solution due to the reduction in the emulsion droplet size. Ballesteros, Ramirez, Orrego, Teixeira and Mussatto [36] demonstrated that encapsulation efficiency was strongly affected by different types of encapsulated compounds. Therefore, it can be concluded that the specific concentration of saffron extract as a core material, the use of different types of bioactive compounds of saffron extract, and the use of different encapsulation techniques had a significant effect on the EE of saffron within the gelatin.

Two-way ANOVA showed that the encapsulation efficiency was significantly affected by the concentration and type of bioactive compound in saffron $(p<0.05)$. It was also found that there was an interaction between the concentration and bioactive compounds of saffron that influenced the encapsulation efficiency $(p<0.01)$.

\subsection{Thermal Analysis}

One of the simplest methods for illustrating the compatibility of polymer is differential scanning calorimetry (DSC) [37]. In this study, DSC was used to investigate the effect of the 
concentration of saffron extract on the thermal behavior of electro-spun gelatin fibers and freeze-dried gelatin particles. The melting temperature $\left(\mathrm{T}_{\mathrm{m}}\right)$, denaturation temperature $\left(T_{d}\right)$, and enthalpy $(\Delta H)$ of saffron extract and gelatin fibers with and without saffron extract are presented in Table 3. All samples showed an endothermic peak due to the breakage of hydrogen bonds [37]. The denaturation temperature $\left(\mathrm{T}_{\mathrm{d}}\right)$ measures the thermal stability of protein [45]. Therefore, denatured protein shows low $\mathrm{T}_{\mathrm{d}}$, while compact and tight protein molecules in a network structure indicate high $\mathrm{T}_{\mathrm{d}}$ [46]. Melting temperature is another thermodynamic property of materials. It is related to the beginning of denaturation. The melting temperature measures the thermal stability of materials. Thus, it will be high at high thermal stability [46].

Table 3. Thermal properties (melting temperature, denaturation temperature, and enthalpy) of electro-spun gelatin fibers and freeze-dried gelatin particles with and without saffron extract.

\begin{tabular}{ccccc}
\hline Encapsulation Technique & Sample & $\mathbf{T m}\left({ }^{\circ} \mathbf{C}\right)$ & $\mathbf{T d}\left({ }^{\circ} \mathbf{C}\right)$ & $\Delta \mathbf{H ~}(\mathbf{J} / \mathbf{g})$ \\
\hline & Saffron extract & $32.1 \pm 2.34^{\mathrm{b}}$ & $36.1 \pm 3.31^{\mathrm{c}}$ & $27.1 \pm 1.66^{\mathrm{d}}$ \\
& Ge fiber & $46.5 \pm 4.06^{\mathrm{c}}$ & $87.7 \pm 5.73^{\mathrm{b}}$ & $415 \pm 8.66^{\mathrm{a}}$ \\
Electrospinning & Ge-S5\% & $55.4 \pm 2.54^{\mathrm{bc}}$ & $90.1 \pm 6.35^{\mathrm{b}}$ & $340 \pm 19.9^{\mathrm{c}}$ \\
& Ge-S10\% & $65.7 \pm 5.27^{\mathrm{ab}}$ & $99.4 \pm 5.72^{\mathrm{ab}}$ & $355 \pm 10.1^{\mathrm{bc}}$ \\
& Ge-S15\% & $78.3 \pm 7.63^{\mathrm{a}}$ & $108 \pm 7.31^{\mathrm{a}}$ & $386 \pm 5.22^{\mathrm{ab}}$ \\
\hline \multirow{5}{*}{ Freeze drying } & Saffron extract & $32.1 \pm 2.34^{\mathrm{b}}$ & $36.1 \pm 3.31^{\mathrm{c}}$ & $27.1 \pm 1.66^{\mathrm{d}}$ \\
& Ge particle & $36.7 \pm 3.89^{\mathrm{b}}$ & $73.8 \pm 3.77^{\mathrm{b}}$ & $86.0 \pm 4.55^{\mathrm{a}}$ \\
& Ge-S5\% & $42.2 \pm 5.78^{\mathrm{b}}$ & $79.1 \pm 5.65^{\mathrm{ab}}$ & $76.1 \pm 4.45^{\mathrm{ab}}$ \\
& Ge-S10\% & $57.9 \pm 6.43^{\mathrm{a}}$ & $89.3 \pm 10.1^{\mathrm{ab}}$ & $66.5 \pm 5.22^{\mathrm{bc}}$ \\
& Ge-S15\% & $65.4 \pm 4.62^{\mathrm{a}}$ & $93.2 \pm 7.25^{\mathrm{a}}$ & $61.2 \pm 3.47^{\mathrm{c}}$ \\
\hline
\end{tabular}

Small letters within the same column of each method indicate significant differences $(p<0.05)$. Capital letters within the same row of each method indicate significant differences $(p<0.05)$.

The melting temperature, denaturation temperature, and enthalpy of pure saffron extract powder appeared at $32{ }^{\circ} \mathrm{C}, 36{ }^{\circ} \mathrm{C}$, and $27 \mathrm{~J} / \mathrm{g}$, respectively (Table 3). These values were significantly lower than the $T_{m}, T_{d}$, and enthalpy of encapsulated $15 \%$ saffron extract in the gelatin matrix. In this study, the melting temperatures of 5, 10, and $15 \%$ encapsulated saffron extracts in electro-spun gelatin fibers were $55.4,65.7$, and $78.3{ }^{\circ} \mathrm{C}$, respectively, while the melting temperatures of the encapsulated saffron extracts in freeze-dried gelatin particles were $42.2,57.9$, and $65.4^{\circ} \mathrm{C}$ at 5,10 , and $15 \%$ saffron extracts, respectively. These findings were in agreement with the results of Carmona, et al. [47,48]. They studied the thermal properties of different saffron samples and reported approximately the same values for $\mathrm{T}_{\mathrm{d}}\left(10\right.$ to $\left.40^{\circ} \mathrm{C}\right)$ and enthalpy (16 to $\left.25 \mathrm{~J} / \mathrm{g}\right)$.

The denaturation temperatures of electro-spun gelatin fibers and freeze-dried gelatin particles without saffron extract were 87.7 and $73.8^{\circ} \mathrm{C}$, respectively, which were related to the helix-to-coil transition [49]. Freeze-dried gelatin particles without saffron contained the highest denatured protein compared to Ge-S5\%, Ge-S10\%, and Ge-S15\% due to their low $T_{d}$. The results showed that the $T_{m}$ and $T_{d}$ of control samples increased as a result of the addition of saffron extract. This finding may be due to the new chemical bonding formed between the molecules of gelatin and saffron, which could have increased the molecular chain. This would have led to a larger and stronger molecular chain increasing the thermal stability and melting temperature. Additionally, the sizes of polymer arrangements affect the melting point rather than the actual\% crystallinity. Moreover, van der Waals Forces and voluminous side groups that hinder the free movements of the chains can increase the melting points. Electro-spun gelatin fibers containing $15 \%$ saffron extract had the highest $\mathrm{T}_{\mathrm{m}}$ and $\mathrm{T}_{\mathrm{d}}$, which led to the highest thermal stability.

The enthalpy shows the required energy to break covalent bonds, hydrogen bonds, and Van der Waals interactions. It also presents the degree of un-denatured structure of protein, crystallinity, or the triple-helical content $[50,51]$. The higher the $\Delta H$, the less denatured the protein. It is known that more thermal energy is required to complete 
protein denaturation [46]. DSC analysis of the samples demonstrated that the enthalpy of un-encapsulated saffron extracts increased significantly from 27 to 340,354 , and $385 \mathrm{~J} / \mathrm{g}$, respectively, as a result of the encapsulation of 5,10 , and $15 \%$ saffron extract into gelatin through the electrospinning process. Moreover, the encapsulation of 5, 10, and $15 \%$ saffron extracts through the freeze drying technique caused the enthalpy of un-encapsulated saffron extracts to increase significantly from 27 to $76,66.5$, and $61.1 \mathrm{~J} / \mathrm{g}$, respectively. Furthermore, the enthalpy of different treatments containing saffron extract reduced with the increase in the saffron extract concentration. [52] reported that the reduction in enthalpy was related to the breaking of hydrogen bonds and the generation of covalent bonds during the encapsulation process.

According to the DSC curves, the $T_{m}$ and $T_{d}$ of gelatin fibers and gelatin particles increased, while the $\Delta \mathrm{H}$ decreased when the saffron extract content increased from 5 to $15 \%$ (Table 3). This might be due to the reduction in possible interactions between water and gelatin molecules. Shao, Niu, Chen and Sun [37] reported that the formation of hydrogen bonding and inter-molecular complexes between bioactive compounds and polysaccharides prevented the interaction of polyelectrolyte and water.

Overall, different concentrations of saffron extract $(5,10$, and $15 \%)$ had a significant effect $(p<0.05)$ on the $T_{m}, T_{d}$, and $\Delta H$ values of different treatments. Since there were no secondary peaks or phase segregation in gelatin fibers or particles containing saffron extract, it can be concluded that the saffron extract was encapsulated into the electro-spun gelatin fibers and freeze-dried gelatin particles homogeneously [53]. It can be concluded that the electrospinning technique may have changed the crystalline structure of the saffron compounds to an amorphous state in gelatin fibers, which led to the disappearance of the endothermic peaks of the saffron extract in the DSC curve of the saffron extract that was encapsulated into gelatin fibers.

\subsection{Storage Stability of Encapsulated Saffron Extract}

The stability of the encapsulated and un-encapsulated saffron extract as a control sample was evaluated in terms of coloring strength under various storage conditions (4, 24 , and $35{ }^{\circ} \mathrm{C}$ ) during 42 days storage. Figure 3 shows the retention of crocin at different temperatures during storage. The degradation of encapsulated and un-encapsulated saffron extract showed a first-order kinetic reaction with a gradual reduction in the concentrations of crocin with respect to time [42]. The reaction rate constant $(k)$ and half-life $\left(t_{1 / 2}\right)$ time of the encapsulated and un-encapsulated crocin in saffron extract at various temperatures were calculated and are shown in Table 4.

Table 4. Regression analysis of crocin stability in electro-spun gelatin fiber and freeze-dried gelatin particles during storage at different temperatures for 42 days of storage.

\begin{tabular}{cccccc}
\hline $\begin{array}{c}\text { Encapsulation } \\
\text { Technique }\end{array}$ & Sample & $\begin{array}{c}\text { Temperature } \\
\left({ }^{\circ} \mathbf{C}\right)\end{array}$ & $\mathbf{t} \frac{1}{2}$ (day) & $\begin{array}{c}\left(\mathbf{k} \times \mathbf{1 0}^{-\mathbf{2}}\right) \\
\left(\mathbf{m i n}^{-\mathbf{1})}\right.\end{array}$ & $\mathbf{R 2}$ \\
\hline & Control & 4 & 22.4 & 3.1 & 0.98 \\
& Ge-S5\% & 4 & 53.3 & 7.3 & 0.94 \\
& Ge-S10\% & 4 & 77 & 0.9 & 1 \\
& Ge-S15\% & 4 & 138 & 0.5 & 0.95 \\
Electrospinning & Control & 24 & 21 & 3.3 & 0.96 \\
& Ge-S5\% & 24 & 40 & 1.7 & 1 \\
& Ge-S10\% & 24 & 86.6 & 0.8 & 1 \\
& Ge-S15\% & 24 & 18.7 & 3.7 & 1 \\
& Control & 35 & 31.5 & 2.2 & 1 \\
& Ge-S5\% & 35 & 38.5 & 1.8 & 1 \\
\end{tabular}


Table 4. Cont.

\begin{tabular}{cccccc}
\hline $\begin{array}{c}\text { Encapsulation } \\
\text { Technique }\end{array}$ & Sample & $\begin{array}{c}\text { Temperature } \\
\left({ }^{\circ} \mathbf{C}\right)\end{array}$ & $\mathbf{t} \frac{1}{2}$ (day) & $\begin{array}{c}\left(\mathbf{k} \times \mathbf{1 0}^{-\mathbf{2}}\right) \\
\left(\mathbf{m i n}^{-\mathbf{1}}\right)\end{array}$ & $\mathbf{R 2}$ \\
\hline & Control & 4 & 22.4 & 3.1 & 0.98 \\
& Ge-S5\% & 4 & 43.3 & 1.6 & 1 \\
& Ge-S10\% & 4 & 57.8 & 7.2 & 0.98 \\
Freeze drying & Ge-S15\% & 4 & 21 & 0.9 & 0.97 \\
& Control & 24 & 34.7 & 2.3 & 0.96 \\
& Ge-S5\% & 24 & 43.3 & 1.6 & 0.97 \\
& Ge-S10\% & 24 & 49.5 & 1.4 & 0.97 \\
& Ge-S15\% & 24 & 18.7 & 3.7 & 0.97 \\
& Control & 35 & 27.7 & 2.5 & 0.98 \\
& Ge-S5\% & 35 & 33 & 2.1 & 0.97 \\
\hline
\end{tabular}

(a)

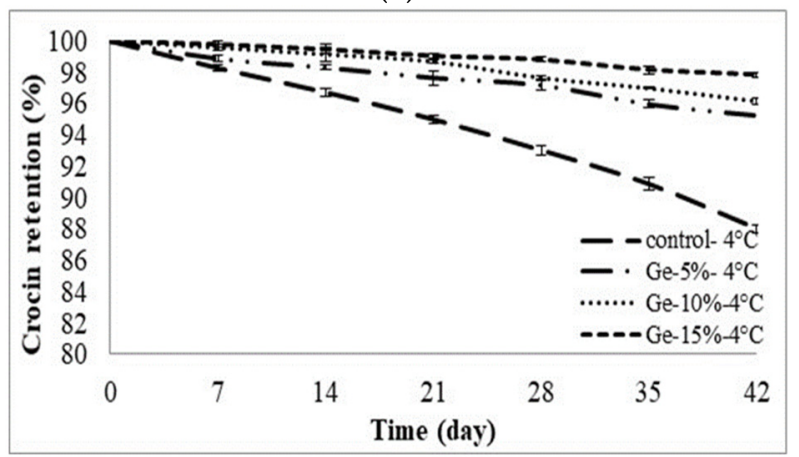

(c)

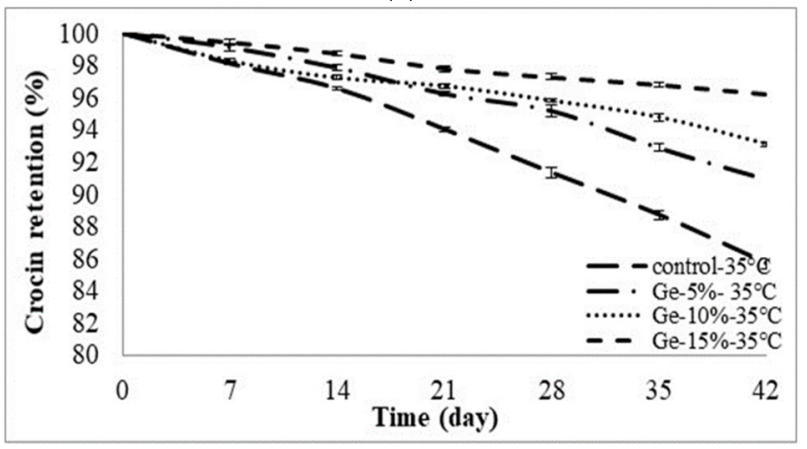

(e)

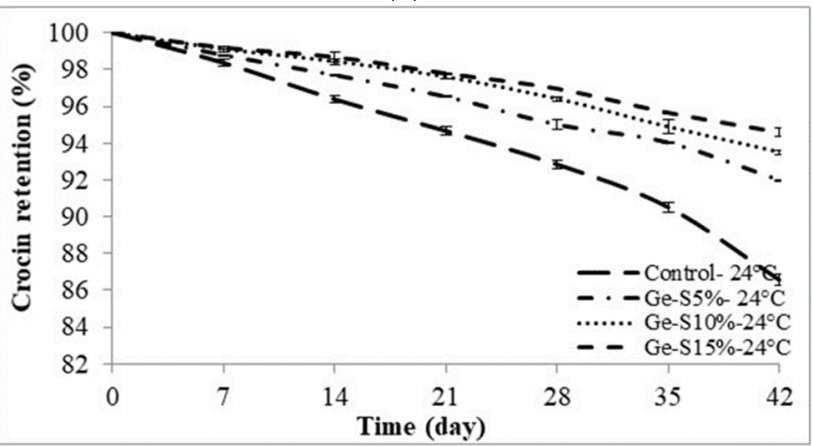

(b)

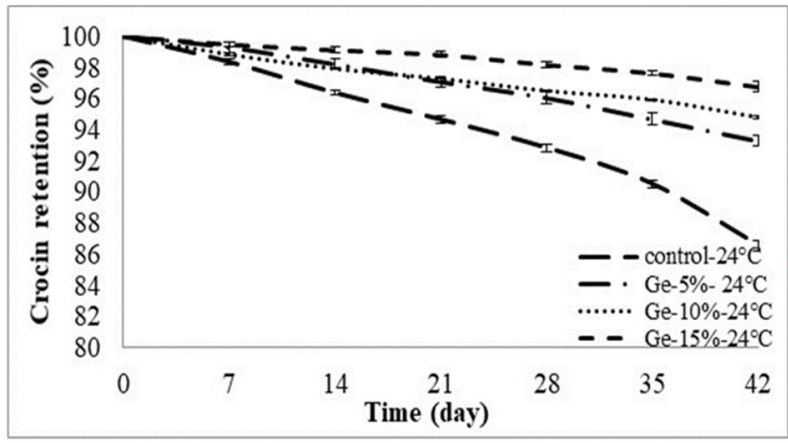

(d)

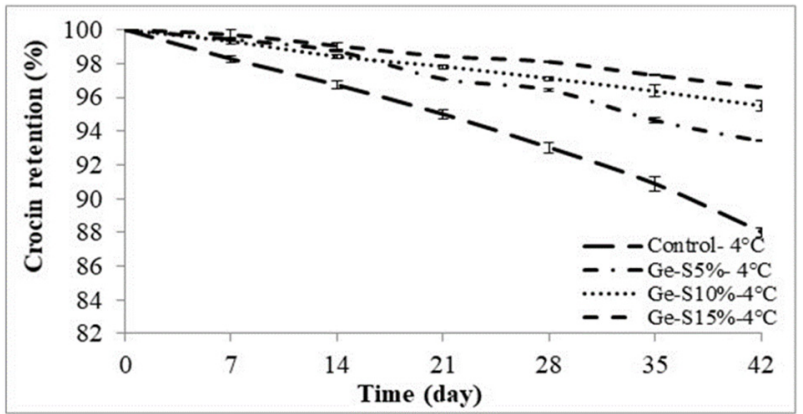

(f)

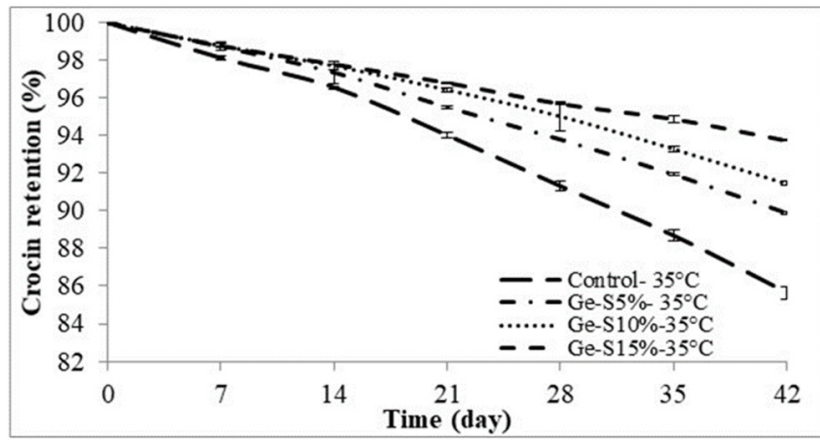

Figure 3. Storage stability of crocin in electro-spun gelatin fibers $(\mathbf{a}-\mathbf{c})$ and freeze-dried gelatin powder $(\mathbf{d}-\mathbf{f})$ under different temperatures.

Overall, the amount of encapsulated crocin at $15 \%$ saffron extract concentration stored at 35, 24 and $4{ }^{\circ} \mathrm{C}$ under constant $\mathrm{RH}(33 \%)$ was significantly higher than for the nonencapsulated saffron extract (control sample) during 6 weeks of storage. In addition, all samples (encapsulated and un-encapsulated) showed a significant difference $(p<0.05)$ in 
terms of the crocin content of electro-spun gelatin fibers and freeze-dried gelatin powders immediately at the first day and after sixth week (day 42). Regarding the effect of temperature on crocin stability during storage, there were significant differences $(p<0.05)$ between the samples stored at three different storage conditions. The results showed that increasing the temperature from 4 to $35^{\circ} \mathrm{C}$ caused a significant decrease in the crocin content of the samples. The crocin content of $15 \%$ saffron extract in the electro-spun gelatin fibers and the control sample decreased by $4 \%$ and $15 \%$, respectively, after 42 days of storage at $35^{\circ} \mathrm{C}$, while in freeze-dried particles at the same storage temperature $\left(35^{\circ} \mathrm{C}\right)$, the reductions were in the order of $7 \%$ and $15 \%$, respectively, over the same period of time. The highest crocin content was observed in the electro-spun fibers containing $15 \%$ saffron extract at $4{ }^{\circ} \mathrm{C}$.

Temperature plays an important role in the stability of bioactive compounds due to oxygen permeability and thermal degradation processes [54]. At higher temperature, molecular interactions increase and molecules have more energy to overcome the activation barrier to initiate the chemical and physical degradations of materials. Therefore, the higher crocin content of the encapsulated saffron extract was related to the presence of gelatin as a wall material creating a physical barrier against destructive agents. Azarpazhooh, Sharayei, Zomorodi and Ramaswamy [9] also reported that the degradation of the encapsulated anthocyanin in maltodextrin, using the freeze drying technique, increased when the storage temperature increased from 4 to $25^{\circ} \mathrm{C}$. Similar results were reported by Fang and Bhandari [55] regarding the storage stability of bayberry polyphenols.

The encapsulated samples showed a lower reaction rate constant and, consequently, a higher half-life period for 42 days of storage at $4{ }^{\circ} \mathrm{C}$ compared to the samples stored at 24 and $35{ }^{\circ} \mathrm{C}$ at the same concentration of saffron extract. The results showed that the half-life period of crocin was influenced by the concentration of saffron extract and the storage temperature. Therefore, by increasing the concentration of saffron extract in electro-spun gelatin fibers and freeze-dried gelatin powders, the reaction rate constant decreased and the half-life period increased. For instance, when using the electrospinning method, $15 \%$ saffron extract exhibited the highest half-life $\left(\mathrm{t}_{1 / 2}\right)$ with the value of 138 days for crocin at $4{ }^{\circ} \mathrm{C}$ under $33 \% \mathrm{RH}$.

Several researchers also found a first-order kinetic reaction for the degradation of saffron carotenoids such as crocin during storage at different temperatures and water activity conditions [32,48]. Rodriguez-Amaya [56] reported that the degradation of carotenoids in food is mainly due to the enzymatic or nonenzymatic oxidation during processing and storage. The color of food can be changed via the isomerization of trans-carotenoids to cis-isomers, which is increased with exposure to oxygen, acids, light, moisture, and heat. $\mathrm{Shu}$, et al. [57] found that through the encapsulation of lycopene in sucrose and gelatin (as the wall materials) using the spray-drying technique, followed by storage at $0{ }^{\circ} \mathrm{C}$ in the presence of light, the amount of lycopene decreased by only $15 \%$ after 28 days storage. Silva, et al. [58] reported that by increasing the concentration of microencapsulated lycopene in gelatin and pectin through the freeze drying method, the stability of lycopene improved compared to the un-encapsulated lycopene during storage, which was similar to the results observed in this study. In addition, they found that by increasing the storage temperature from 10 to $25^{\circ} \mathrm{C}$, the concentration of lycopene in freeze-dried powder decreased. Jafari, et al. [59] concluded that encapsulation techniques protect sensitive ingredients against oxygen, light, heat, and moisture since the wall materials act as a barrier and decrease the effect of environmental conditions. Another factor that can influence the stability of encapsulated compounds during storage is moisture content. Tonon, et al. [60] reported that a reduction in the moisture content of the environment during storage leads to the decreasing molecular mobility of the encapsulating agent in the glassy state.

Generally, the results demonstrated that the storage stability of encapsulated and un-encapsulated crocin was significantly $(p<0.05)$ affected by the concentration of saffron extract, time, temperature, and their interactions. The results confirmed the good efficiency of electrospinning and freeze drying for the protection of natural pigments of saffron during storage as the most common encapsulation technique. 


\section{Conclusions}

The results of this study show that gelatin could be used as a wall material for the encapsulation of saffron via two different techniques. The viscosity of gelatin solutions did not change significantly with the increasing of the saffron extract concentration from 5 to $15 \%$. The SEM images showed that the extract-loaded fibers and particles had similar morphologies as the neat electro-spun gelatin fibers and gelatin particles, respectively. The encapsulated extract in gelatin fibers showed a smooth, bead-free, and homogeneously distributed morphology, while freeze-dried gelatin powders exhibited very large particle sizes with irregular structures, indentations, and cracks.

Encapsulation efficiency determined that the saffron extract was successfully encapsulated in fibers and particles, with high encapsulation efficiency, using the electrospinning and freeze drying methods. The melting temperature, denaturation temperature, and enthalpy of saffron extracts increased significantly $(p<0.05)$ with the encapsulation of saffron in gelatin. The results revealed that the encapsulated saffron extract in gelatin fibers and gelatin particles showed higher retention of crocin compared to the non-encapsulated extract during the 42 days of storage at 4,24 , and $35^{\circ} \mathrm{C}$. Moreover, the amount of encapsulated crocin in all samples decreased with the passage of storage time.

The results also demonstrated that the degradation of crocin significantly increased $(p<0.05)$ with the increasing of the storage temperature. Therefore, the highest crocin content was observed in the electro-spun gelatin fibers and freeze-dried gelatin powders containing $15 \%$ saffron extract at $4{ }^{\circ} \mathrm{C}$, while the encapsulated saffron extracts at $5 \%$ showed the lowest retention of crocin in gelatin fibers and gelatin powders at $35{ }^{\circ} \mathrm{C}$ during the 42 days of storage. The crocin degradation followed the first-order kinetic reaction. Encapsulated crocin showed a half-life period $\left(\mathrm{t}_{1 / 2}\right)$ with values of 138 and 77 days, respectively, for $15 \%$ saffron extract under $4{ }^{\circ} \mathrm{C}$ when using the electrospinning and freeze drying techniques.

Overall, among the different concentrations (5,10, and 15\%) of saffron extract as a core material, $15 \%$ saffron extract provided better encapsulation efficiency, thermal properties, and storage stability. This study also indicated that encapsulation by electrospinning technique is more effective than freeze drying to improve the encapsulation efficiency, thermal properties, and retention of crocin content over a period of 42 days of storage. This phenomenon may be due to the breaking of wall materials and the loss of the initial structure of gelatin capsules during the freeze drying and grinding procedure. Therefore, encapsulation by electrospinning could be recommended as a proper technique for stabilizing bioactive compounds of saffron during processing and storage. Accordingly, it can be concluded that the encapsulation of saffron into fine electro-spun fibers can be used in different foods such as desserts, dairy products, chewing gums, beverages, and tea bags.

Author Contributions: Conceptualization, H.S.R., N.M. and F.G.; Data curation, F.G.; Formal analysis, F.G.; Funding acquisition, H.S.R.; Investigation, F.G.; Methodology, H.S.R., N.M. and F.G.; Project administration, H.S.R.; Resources, H.S.R.; Supervision, H.S.R.; Validation, F.G.; Visualization, F.G.; Writing—original draft, F.G.; Writing—review \& editing, H.S.R. and N.M. All authors have read and agreed to the published version of the manuscript.

Funding: This research received no external funding.

Institutional Review Board Statement: Not applicable.

Informed Consent Statement: Not applicable.

Data Availability Statement: The data presented in this study are available on request from the corresponding author.

Conflicts of Interest: The authors declare no conflict of interest. 


\section{References}

1. Fernández, J.A. Biology, biotechnology and biomedicine of saffron. Recent Res. Dev. Plant Sci. 2004, 2, 127-159.

2. Basker, D.; Negbi, M. Uses of saffron. Econ. Bot. 1983, 37, 228-236. [CrossRef]

3. Patras, A.; Brunton, N.P.; O'Donnell, C.; Tiwari, B. Effect of thermal processing on anthocyanin stability in foods; mechanisms and kinetics of degradation. Trends Food Sci. Technol. 2010, 21, 3-11. [CrossRef]

4. Ahmed, M.; Akter, M.S.; Lee, J.C.; Eun, J.B. Encapsulation by spray drying of bioactive components, physicochemical and morphological properties from purple sweet potato. LWT-Food Sci. Technol. 2010, 43, 1307-1312. [CrossRef]

5. Dehcheshmeh, M.A.; Fathi, M. Production of core-shell nanofibers from zein and tragacanth for encapsulation of saffron extract. Int. J. Biol. Macromol. 2019, 122, 272-279. [CrossRef] [PubMed]

6. Kayaci, F.; Uyar, T. Encapsulation of vanillin/cyclodextrin inclusion complex in Electro-spun polyvinyl alcohol (PVA) nanowebs: Prolonged shelf-life and high temperature stability of vanillin. Food Chem. 2012, 133, 641-649. [CrossRef]

7. Jafari, S.M.; Assadpoor, E.; He, Y.; Bhandari, B. Encapsulation efficiency of food flavours and oils during spray drying. Dry. Technol. 2008, 26, 816-835. [CrossRef]

8. Garavand, F.; Rahaee, S.; Vahedikia, N.; Jafari, S.M. Different techniques for extraction and micro/nanoencapsulation of saffron bioactive ingredients. Trends Food Sci. Technol. 2019, 89, 26-44. [CrossRef]

9. Azarpazhooh, E.; Sharayei, P.; Zomorodi, S.; Ramaswamy, H.S. Physicochemical and Phytochemical Characterization and Storage Stability of Freeze-dried Encapsulated Pomegranate Peel Anthocyanin and In Vitro Evaluation of Its Antioxidant Activity. Food Bioprocess Technol. 2019, 12, 199-210. [CrossRef]

10. Desai, K.G.H.; Jin Park, H. Recent developments in microencapsulation of food ingredients. Dry. Technol. 2005, 23, 1361-1394. [CrossRef]

11. Murali, S.; Kar, A.; Mohapatra, D.; Kalia, P. Encapsulation of black carrot juice using spray and Freeze drying. Food Sci. Technol. Int. 2015, 21, 604-612. [CrossRef] [PubMed]

12. Mascarenhas, W.; Akay, H.; Pikal, M. A computational model for finite element analysis of the freeze drying process. Comput. Methods Appl. Mech. Eng. 1997, 148, 105-124. [CrossRef]

13. Ceballos, A.M.; Giraldo, G.I.; Orrego, C.E. Effect of freezing rate on quality parameters of freeze-dried soursop fruit pulp. J. Food Eng. 2012, 111, 360-365. [CrossRef]

14. Buffo, R.A.; Reineccius, G.A. Shelf-life and mechanisms of destabilization in dilute beverage emulsions. Flavour Fragr. J. 2001, 16, 7-12. [CrossRef]

15. Zuidam, N.J.; Shimoni, E. Overview of microencapsulates for use in food products or processes and methods to make them. In Encapsulation Technologies for Active Food Ingredients and Food Processing; Springer: Berlin/Heidelberg, Germany, 2010 ; pp. 3-29.

16. Ahmadian, Z.; Niazmand, R.; Pourfarzad, A. Microencapsulation of saffron petal phenolic extract: Their characterization, in vitro gastrointestinal digestion, and storage Stability. J. Food Sci. 2019, 84, 2745-2757. [CrossRef]

17. Bhardwaj, N.; Kundu, S.C. Electrospinning: A fascinating fiber fabrication technique. Biotechnol. Adv. 2010, $28,325-347$. [CrossRef]

18. Yu, D.; Yang, Y.-Q.; Chen, Z.; Tao, Y.; Liu, Y.-F. Recent progress on thin-film encapsulation technologies for organic electronic devices. Opt. Commun. 2016, 362, 43-49. [CrossRef]

19. Niu, X.; Liu, Z.; Tian, F.; Chen, S.; Lei, L.; Jiang, T.; Fan, Y. Sustained delivery of calcium and orthophosphate ions from amorphous calcium phosphate and poly (L-lactic acid)-based Electrospinning nanofibrous scaffold. Sci. Rep. 2017, 7, 45655. [CrossRef]

20. Huang, Z.-M.; Zhang, Y.-Z.; Kotaki, M.; Ramakrishna, S. A review on polymer nanofibers by electrospinning and their applications in nanocomposites. Compos. Sci. Technol. 2003, 63, 2223-2253. [CrossRef]

21. Mirjalili, M.; Zohoori, S. Review for application of Electrospinning and Electro-spun nanofibers technology in textile industry. J. Nanostruct. Chem. 2016, 6, 207-213. [CrossRef]

22. Alborzi, S.; Lim, L.-T.; Kakuda, Y. Encapsulation of folic acid and its stability in sodium alginate-pectin-poly (ethylene oxide) Electro-spun fibres. J. Microencapsul. 2013, 30, 64-71. [CrossRef] [PubMed]

23. Bhushani, J.A.; Anandharamakrishnan, C. Electrospinning and Electrospraying techniques: Potential food based applications. Trends Food Sci. Technol. 2014, 38, 21-33. [CrossRef]

24. Esfanjani, A.F.; Jafari, S.M.; Assadpoor, E.; Mohammadi, A. Nano-encapsulation of saffron extract through double-layered multiple emulsions of pectin and whey protein concentrate. J. Food Eng. 2015, 165, 149-155. [CrossRef]

25. Rajabi, H.; Ghorbani, M.; Jafari, S.M.; Sadeghi Mahoonak, A.; Rajabzadeh, G. Retention of saffron bioactive components by spray drying encapsulation using maltodextrin, gum Arabic and gelatin as wall materials. Food Hydrocoll. 2015, 51, 327-337. [CrossRef]

26. Horuz, T.I.; Belibağlı, K.B. Nanoencapsulation by electrospinning to improve stability and water solubility of carotenoids extracted from tomato peels. Food chem. 2018, 268, 86-93. [CrossRef]

27. Aceituno-Medina, M.; Mendoza, S.; Lagaron, J.M.; López-Rubio, A. Development and characterization of food-grade Electro-spun fibers from amaranth protein and pullulan blends. Food Res. Int. 2013, 54, 667-674. [CrossRef]

28. Moomand, K.; Lim, L.-T. Oxidative stability of encapsulated fish oil in Electro-spun zein fibres. Food Res. Int. 2014, 62, 523-532. [CrossRef] 
29. Aceituno-Medina, M.; Mendoza, S.; Lagaron, J.M.; López-Rubio, A. Photoprotection of folic acid upon encapsulation in foodgrade amaranth (Amaranthus hypochondriacus L.) protein isolate-Pullulan Electro-spun fibers. LWT-Food Sci. Technol. 2015, 62, 970-975. [CrossRef]

30. Gómez-Guillén, M.C.; Giménez, B.; López-Caballero, M.A.; Montero, M.P. Functional and bioactive properties of collagen and gelatin from alternative sources: A review. Food Hydrocoll. 2011, 25, 1813-1827. [CrossRef]

31. Maftoonazad, N.; Shahamirian, M.; John, D.; Ramaswamy, H. Development and evaluation of antibacterial Electro-spun pea protein isolate-polyvinyl alcohol nanocomposite mats incorporated with cinnamaldehyde. Mater. Sci. Eng. C 2019, 94, 393-402. [CrossRef]

32. Selim, K.A.; Khalil, K.E.; Abdel-Bary, M.S.; Abdel-Azeim, N.A. Extraction, encapsulation and utilization of red pigments from Roselle (Hibiscus sabdariffa L.) as natural food colourants. In Proceedings of the 5th Alexandria Conference of Food and Dairy Science and Technology, Alexandria, Egypt, 4-6 March 2008; pp. 7-20.

33. Hollingworth, T.; Wekell, M.M. Paralytic shellfish poison biological method, final action. In Official Methods of Analysis of AOAC; Hellrich, K., Ed.; AOAC: Arlington, VA, USA, 1990; pp. 881-882.

34. Wang, W.-D.; Xu, S.-Y. Degradation kinetics of anthocyanins in blackberry juice and concentrate. J. Food Eng. 2007, 82, 271-275. [CrossRef]

35. Kaushik, V.; Roos, Y.H. Limonene encapsulation in freeze drying of gum Arabic-sucrose-gelatin systems. LWT-Food Sci. Technol. 2007, 40, 1381-1391. [CrossRef]

36. Ballesteros, L.F.; Ramirez, M.J.; Orrego, C.E.; Teixeira, J.A.; Mussatto, S.I. Encapsulation of antioxidant phenolic compounds extracted from spent coffee grounds by freeze drying and spray-drying using different coating materials. Food Chem. 2017, 237, 623-631. [CrossRef] [PubMed]

37. Shao, P.; Niu, B.; Chen, H.; Sun, P. Fabrication and characterization of tea polyphenols loaded pullulan-CMC Electro-spun nanofiber for fruit preservation. Int. J. Biol. Macromol. 2018, 107, 1908-1914. [CrossRef] [PubMed]

38. Suwantong, O.; Opanasopit, P.; Ruktanonchai, U.; Supaphol, P. Electro-spun cellulose acetate fiber mats containing curcumin and release characteristic of the herbal substance. Polymer 2007, 48, 7546-7557. [CrossRef]

39. Wang, S.; Marcone, M.F.; Barbut, S.; Lim, L.-T. Electro-spun soy protein isolate-based fiber fortified with anthocyanin-rich red raspberry (Rubus strigosus) extracts. Food Res. Int. 2013, 52, 467-472. [CrossRef]

40. Khazaei, K.M.; Jafari, S.; Ghorbani, M.; Kakhki, A.H. Application of maltodextrin and gum Arabic in microencapsulation of saffron petal's anthocyanins and evaluating their storage stability and color. Carbohydr. Polym. 2014, 105, 57-62. [CrossRef]

41. Hogan, S.A.; McNamee, B.F.; O’Riordan, E.D.; O'Sullivan, M. Emulsification and microencapsulation properties of sodium caseinate/carbohydrate blends. Int. Dairy J. 2001, 11, 137-144. [CrossRef]

42. Chranioti, C.; Nikoloudaki, A.; Tzia, C. Saffron and beetroot extracts encapsulated in maltodextrin, gum Arabic, modified starch and chitosan: Incorporation in a chewing gum system. Carbohydr. Polym. 2015, 127, 252-263. [CrossRef]

43. Mahdavi, S.A.; Jafari, S.M.; Assadpoor, E.; Dehnad, D. Microencapsulation optimization of natural anthocyanins with maltodextrin, gum Arabic and gelatin. Int. J. Biol. Macromol. 2016, 85, 379-385. [CrossRef] [PubMed]

44. Chronakis, I.S. Novel nanocomposites and nanoceramics based on polymer nanofibers using Electrospinning process-A review. J. Mater. Process. Technol. 2005, 167, 283-293. [CrossRef]

45. Meng, G.T.; Ma, C.Y. Thermal properties of Phaseolus angularis (red bean) globulin. Food Chem. 2001, 73, 453-460. [CrossRef]

46. Ma, C.Y.; Harwalkar, V.R. Studies of thermal denaturation of oat globulin by differential scanning calorimetry. J. Food Sci. 1988, 53, 531-534. [CrossRef]

47. Carmona, M.; Zalacain, A.; Pardo, J.E.; López, E.; Alvarruiz, A.; Alonso, G.L. Influence of different drying and aging conditions on saffron constituents. J. Agric. Food Chem. 2005, 53, 3974-3979. [CrossRef] [PubMed]

48. Tsimidou, M.; Biliaderis, C.G. Kinetic studies of saffron (Crocus sativus L.) quality deterioration. J. Agric. Food Chem. 1997, 45, 2890-2898. [CrossRef]

49. Tavassoli-Kafrani, E.; Goli, S.A.H.; Fathi, M. Fabrication and characterization of Electro-spun gelatin nanofibers crosslinked with oxidized phenolic compounds. Int. J. Biol. Macromol. 2017, 103, 1062-1068. [CrossRef]

50. Zhang, Y.Z.; Venugopal, J.; Huang, Z.M.; Lim, C.T.; Ramakrishna, S. Crosslinking of the Electro-spun gelatin nanofibers. Polymer 2006, 47, 2911-2917. [CrossRef]

51. Jalaja, K.; James, N.R. Electro-spun gelatin nanofibers: A facile cross-linking approach using oxidized sucrose. Int. J. Biol. Macromol. 2015, 73, 270-278. [CrossRef]

52. Haroun, A.; El Toumy, S. Effect of natural polyphenols on physicochemical properties of crosslinked gelatin-based polymeric biocomposite. J. Appl. Polym. Sci. 2010, 116, 2825-2832. [CrossRef]

53. Li, M.; Guo, Y.; Wei, Y.; MacDiarmid, A.G.; Lelkes, P.I. Electrospinning polyaniline-contained gelatin nanofibers for tissue engineering applications. Biomaterials 2006, 27, 2705-2715. [CrossRef]

54. Andersen, A.B.; Risbo, J.; Andersen, M.L.; Skibsted, L.H. Oxygen permeation through an oil-encapsulating glassy food matrix studied by ESR line broadening using a nitroxyl spin probe. Food Chem. 2000, 70, 499-508. [CrossRef]

55. Fang, Z.; Bhandari, B. Encapsulation of polyphenols-A review. Trends Food Sci. Technol. 2010, 21, 510-523. [CrossRef]

56. Rodriguez-Amaya, D. Effects of processing and storage on food carotenoids. Sight Life Newsl. 2002, 3, $25-35$.

57. Shu, B.; Yu, W.; Zhao, Y.; Liu, X. Study on microencapsulation of lycopene by spray-drying. J. Food Eng. 2006, 76, 664-669. [CrossRef] 
58. Silva, D.F.; Favaro-Trindade, C.S.; Rocha, G.A.; Thomazini, M. Microencapsulation of lycopene by gelatin-pectin complex coacervation. J. Food Process. Preserv. 2012, 36, 185-190. [CrossRef]

59. Jafari, S.M.; He, Y.; Bhandari, B. Encapsulation of nanoparticles of d-limonene by spray drying: Role of emulsifiers and emulsifying techniques. Dry. Technol. 2007, 25, 1069-1079. [CrossRef]

60. Tonon, R.V.; Brabet, C.; Hubinger, M.D. Anthocyanin stability and antioxidant activity of spray-dried açai (Euterpe oleracea Mart.) juice produced with different carrier agents. Food Res. Int. 2010, 43, 907-914. [CrossRef] 